\title{
WHAT FORM OF RELATIVE PERFORMANCE EVALUATION?*
}

\author{
Marco Celentani ${ }^{\dagger}$ and Rosa Loveira
}

JANUARY, 2004

\begin{abstract}
We study relative performance evaluation in executive compensation when executives have private information about their ability. We assume that the joint distribution of an individual firm's profit and market movements depends on the ability of the executive that runs the firm. In the equilibrium of the executive labor market, compensation schemes exploit this fact to sort executives of different abilities. This implies that executive compensation is increasing in own performance, but may also be increasing in industry performance-a sharp departure from standard relative performance evaluation. This result provides an explanation for the scarcity of relative performance considerations in executive compensation documented by the empirical literature.
\end{abstract}

Jel Classification: D82, G30, J33, M52.

KEYWORDS: Executive compensation, relative performance evaluation

\section{Introduction}

Academics, practitioners and the business press frequently recommend the use of relative performance evaluation (RPE) in executive compensation packages. RPE is normally taken to mean that executive compensation is increasing in own performance and decreasing in performance of an appropriately defined peer group. RPE may be seen as a consequence of Holmström's $(1979,1982)$ informativeness principle that stipulates that in a principal-agent relationship all informative signals should be included in contracting: "one can improve risk sharing while at the same time retaining incentives." ${ }^{1}$ When designing executive compensation, this principle may be argued to imply that "managers are not held responsible for events one can observe are outside of their control, and [...] their performance is always judged against information about what should be achievable given, say, the current economic situation." ${ }^{2}$

These principles are very popular in the business press. According to Rappaport (1999): "Shareholders expect boards to reward management for achieving superior returns-that is, for returns equal to or better than those earned by the company's peer group or by broader market indexes." ${ }^{3}$ Dobbs and Koller (2000) warn that "compensations plans linking the pay of managers to the share values of their companies can reward or penalize them for events they don't control." ${ }^{4}$ For The Economist (2002) "rewards linked to a company share price should probably be triggered only if the firm outperforms the market as a whole, or an industry peer group." ${ }^{5}$ The Financial Economist Roundtable maintains that "executives should not be

\footnotetext{
* Marco Celentani gratefully acknowledges the financial support of Fundación BBVA, Fundación Ramón Areces, and MCYT (Spain) under project BEC2002-03715. Rosa Loveira gratefully acknowledges the financial support of MCYT (Spain) under project BEC2002-03715. We thank Pier Paolo Battigalli, Alberto Bennardo, Alberto Bisin, Michele Boldrin, Guillermo Caruana, Francesco De Sinopoli, Jordi Jaumandreu, Belén Jerez, Wolfgang Pesendorfer, Pablo Ruiz-Verdú and Seminar Participants at Università Bocconi, Universidad Carlos III, and Ente Einaudi for useful discussions and suggestions.

${ }^{\dagger}$ Department of Economics, Universidad Carlos III, Getafe (Madrid) 28903, Spain; fax +34-91-624 9875; marco.celentani@uc3m.es.

${ }^{\ddagger}$ Department of Economics, Universidad Carlos III, Getafe (Madrid) 28903, Spain and Department of Economics and Business, Universitat Pompeu Fabra, Carrer Ramón Trías Fargas, 23-27, 08005, Barcelona, Spain; fax: +34-93-542 1746; rosa.loveira@upf.edu.

${ }^{1}$ Holmström (1979), page 87 .

${ }^{2}$ Holmström (1979), page 82.

${ }^{3}$ Rappaport (1999), page 92.

${ }^{4}$ Dobbs and Koller (2000), page 190.

${ }^{5}$ The Economist (2002), page 25 .
} 
rewarded or punished for outcomes that are beyond their control" and that their "compensation schemes may include some form of indexation as a means of relating pay to the component of performance that is more directly within the control of executives." 6

Despite the general praise of RPE, the extensive empirical research dedicated to its study has produced surprisingly little evidence of a negative relationship between executive compensation and market movements. Some studies have even found a positive relationship. ${ }^{7}$ Summarizing the results of the empirical investigation on RPE, Murphy (1999) says that "the paucity of RPE considerations in [...] executive compensation remains a puzzle worth understanding." According to Hall and Liebman (1998) "the near complete absence of relative pay seems to be a puzzle." 8 Recent reviews of the compensation literature, Abowd and Kaplan (1999) and Prendergast (1999), also indicate the lack of RPE as a major unsettled problem.

The absence of RPE in executive compensation has also been noted by the business press which has frequently expressed dissatisfaction with current compensation practices. The Economist (2002) asks "If a firm's share price goes up for extraneous reasons-a fall in interest rates, say, or a rise in the stock marketwhy should the managers benefit?" 9 de Swaan and Harper (2003) note that "In case after case, investors have seen executives reap extraordinary rewards tied to share price increases that had little to do with management and everything to do with factors beyond its control, such as interest rate movements and changes in macroeconomic conditions."

The purpose of the present paper is to provide a theoretical model to study executive compensation and to show that RPE is an important compensation tool, but that it may take a form that differs from the one advocated by the existing literature. In particular, we show that there are cases in which executive compensation is increasing in market performance.

We study a situation in which firms compete for risk averse managers who have private information about their individual ability. The probability distribution over a firm's performance depends on the ability of its manager, but also on a common aggregate state (when the aggregate state is favorable, a firm is more likely to experience success). To avoid unnecessary complications we assume that the individual performance and the aggregate state are both publicly observable and we allow executive compensation to be made dependent on both.

We find that in contracts accepted in equilibrium executive compensation depends on own performance and on the aggregate state, but that it may be increasing in the latter, in the sense that executive compensation may be higher when the aggregate state is favorable and therefore when aggregate performance is higher. The intuition behind our result can be explained as follows. Managers of different abilities generate different probability distribution over states, i.e., over pairs of individual and aggregate performance. This implies that no equilibrium may exist in which both types of manager accept the same contract. If this were the case, a firm could profit from screening out a good manager by offering a contract that increases compensation in a state which is relatively more likely for the good manager and decreases it in a state which is relatively less likely for him.

If an equilibrium exists, then, it has to be separating in the sense that the contracts accepted by the two types are different. These results are reminiscent of the insurance market with adverse selection studied by Rothschild and Stiglitz (1976) and Wilson (1977). As in that case, risk aversion implies that in equilibrium the bad manager accepts a contract that fully insures him. The contract accepted by the good type is the contract that the good type most prefers among the ones that break even, and are such that the bad type prefers his own contract.

In Rothschild and Stiglitz (1976) the good type has incomplete insurance and therefore has higher consumption in the state that is relatively more likely for him, i.e., the no-loss state. In a similar way, we find that compensation to the good manager is higher in states that are relatively more likely for him than for the bad type. But we also find that, because of correlation between market and individual outcomes, the likelihood of a given level of own performance with a favorable aggregate state relative to the same

\footnotetext{
${ }^{6}$ Financial Economist Roundtable (2003), page 7.

${ }^{7}$ See, for instance Antle and Smith (1986), Gibbons and Murphy (1990), Barro and Barro (1990), Janakirman, Lambert and Larcker (1992), Joh (1999), Aggarwal and Samwick (1999a and b). For additional discussion of the empirical literature, refer to the surveys of Rosen (1992), Prendergast (1999) or Murphy (1999).

${ }^{8}$ Hall and Liebman (1999), page 683, footnote 34.

${ }^{9}$ The Economist (2002), page 25.
} 
level of performance with an unfavorable aggregate state may be higher for a good manager than for a bad one. This implies that the contract accepted in equilibrium by a good manager may stipulate that for a given level of own performance executive compensation is higher with a favorable than with an unfavorable aggregate state. In other words, we find that executive compensation is increasing in the firm's absolute performance but is not necessarily decreasing with industry performance. We analyze the implications of our results by running a regression on the data generated by the model and we show that our results can generate a positive relationship between executive compensation and aggregate performance.

Our results show that principle of not rewarding or punishing executives for events beyond their control needs to be read cautiously. If one takes the view that this principle means that compensation should be decreasing in market performance, our results show that the principle does not hold in a very simple and standard environment. A less simplistic reading would view the principle as popularizing the idea that the optimal provision of incentives requires compensation schemes that evoke a statistical interpretation. This means that compensation has to be higher when there is more evidence that the agent has acted as the principal wished (as in a moral hazard environment) or that he is of a desirable type (as in an adverse selection environment). When viewed in these more general terms, the principle, however, may produce opposite recommendations for different environments.

For example, when corporate performance is additive in a market shock component, it seems reasonable to filter out market risk by rewarding the executive when market performance is bad and punishing him when market performance is good, as often advocated. But in an adverse selection example that we analyze in the paper, conditional on individual success, a good manager may be paid more when market performance is good rather than bad. Rewarding the executive with individual success and a favorable aggregate state may contradict conventional wisdom, but seems justified if this combination of own and aggregate performance provides compelling evidence that he has given the contribution that only a good executive can give.

Holmström's (1979 and 1982) Informativeness Principle formalized the idea that the provision of incentives may be improved by making pay contingent on market performance, but it gave no indication of the sign of this relationship. Several authors interested in the relationship between executive compensation and market movements have acknowledged this ambiguity. For Antle and Smith (1986) "the shape of the contract is a function of properties of the monitoring system, the utility functions of the principal and the agent, the production environment, and the cost of writing contingencies into the contracts. Not all of these parameters are observable by the researcher." Gibbons and Murphy (1990) also warn that "agency theory predicts that compensation will depend on relative performance evaluation but gives little guidance as to the form of the contract."

Even in the absence of unambiguous theoretical guidance, empirical research has tried to assess whether executive compensation is monotonically increasing or decreasing in market movements and has found mixed results. ${ }^{10}$ The apparent absence of RPE considerations in executive compensation has received a great deal of attention in recent empirical and theoretical research.

Garvey and Milbourn (2003) and Core and Guay (2002) have pointed out that the exposure to risk of executive compensation packages is only part of executives' total exposure to risk. When executive compensation does not filter out market risk, the executive can reduce his exposure to market risk by reducing the exposure to risk of the rest of his financial wealth. Garvey and Milbourn (2003) find some evidence of RPE for younger executives, who are likely to be less able to filter out market risk because they have less wealth.

Several authors have proposed the idea that, because compensation influences managers' decisions in product markets, optimal managerial compensation should take into account this effect when firms operate in imperfectly competitive markets. This idea, first proposed by Salas Fumás (1992), has been pursued by Aggarwal and Samwick (1999a) and by Joh (1999) that have found empirical evidence of managerial compensation being increasing in industry performance rather than decreasing. They also find that the sensitivity of managerial compensation to industry performance is larger in more competitive environments. Aggarwal and Samwick (1999a) reconcile this finding with price rather than quantity competition and Joh (1999) underlines that the usefulness of strategic group performance evaluation (in opposition to RPE) to sustain collusion in product markets is larger in a more competitive setting.

\footnotetext{
${ }^{10}$ See the references in footnote 7 .
} 
Bebchuk, Fried, and Walker (2002) argue that executive compensation is best explained as rent extraction subject to a constraint on the "'outrage" [executive] pay packages would create." Market or sector indexing are argued to be unattractive for several reasons, including that they are more likely to highlight inferior performance and that the value of indexed options has to be charged against earnings whereas standard option awards only appear in the footnotes of financial statements.

Himmelberg and Hubbard (2000) point out that aggregate shocks simultaneously raise firms' values and the marginal values of CEO services to firms. Given that the supply of talented CEO capable of running large and complex corporations is relatively inelastic, these shocks bid up the value of their compensation packages and make it appear as if RPE is violated. In a similar vein, Oyer (2003) points out that there may be positive correlation between workers' outside opportunities and firms' market values. In such an environment, when it is costly to revise labor contracts, a profit sharing scheme that does not filter out aggregate risk, is employed as a way to index compensation to market conditions and, therefore, automatically meet workers' participation constraints.

The previous works view performance-pay only as a means to provide executives with incentives to make decisions in the interest of shareholders, but have disregarded its sorting effects. Our paper differs substantially from them because we take the complementary standpoint and analyze executive compensation only as an instrument to sort managers of different abilities. In doing so we subscribe to the widely held view that executive compensation is designed more as a way to retain executives with superior abilities or induce them to make decisions in the interest of shareholders, than as an attempt to provide lazy managers with incentives to work hard. ${ }^{11}$

Despite the obvious modeling differences, we view our research as most related to Himmelberg and Hubbard (2000) and Oyer (2003) because we also attempt to explain compensation schemes as arising from executive labor market rather than from product market interactions.

The paper is organized as follows. Section 2 presents the model and introduces the equilibrium concept used in the paper. Section 3 characterizes the equilibrium. Section 4 studies the implications of the equilibrium analysis of section 3 on the link between managerial pay and firms' performance measures and discusses an extension of the model in which a manager may be one of a finite number of types. Section 5 concludes.

\section{The Model}

A population of risk neutral firms compete for scarce risk averse managers. Each manager has private information about his individual ability. To simplify the presentation we will assume that two firms compete for every single manager. When a firm hires a manager it may have two possible realizations of revenue (gross of executive pay), success, with revenue $s>0$, or failure, with 0 revenue. We denote the publicly observable realization of revenue by $P \in\{F, S\}$, where $F$ and $S$ indicate a failure or a success, respectively. For simplicity, we assume that only two types of managers exist, good and bad, $\tau \in\{G, B\}$, and we denote by $\mu \in(0,1)$ the probability that the manager is good. When a firm hires a bad manager, its probability of success is $p$. When a firm hires a good manager, its probability of success is $p+\gamma$, with $\gamma \in(0,1-p)$ which implies that the probability of success is higher when the firm is run by a good manager rather than by a bad one. We normalize to $\tilde{\pi}<p s$ the profit of a firm that does not succeed in hiring a manager.

We introduce correlation among firms' performances by assuming that an aggregate state of nature $\Pi$ $\in\{\underline{\Pi}, \bar{\Pi}\}$ determines the probability of success of individual firms' investment project. In the favorable aggregate state, $\bar{\Pi}$, the probability of success is $\bar{p}+\bar{\gamma}>p+\gamma$ when the firm is run by a good manager and $\bar{p}>p$ when the firm is run by a bad manager. In the unfavorable aggregate state, $\underline{\Pi}$, the probability of success is $\underline{p}+\underline{\gamma}<p+\gamma$ when the firm is run by a good manager and $\underline{p}<p$ when the firm is run by a bad manager. We denote the probability of state $\bar{\Pi}$ by $\bar{\beta}$ and the probability of state $\underline{\Pi}$ by $\beta=1-\bar{\beta}$. Given that the unconditional probability of success is $p+\gamma$ or $p$ depending on the firm being run by a good or a

\footnotetext{
${ }^{11}$ According to Murphy (1999, page 2521) "the reason shareholders entrust their money to self-interested CEOs is based on shareholder beliefs that CEOs have superior skills or information in making investment decisions." For similar arguments see also Holmström and Ricart i Costa (1986), Ricart i Costa (1989), Core and Guay (2000), or Prendergast (2002).
} 
bad manager respectively, we have

$$
\begin{aligned}
(\bar{p}+\bar{\gamma}) \bar{\beta}+(\underline{p}+\underline{\gamma})(1-\bar{\beta}) & =p+\gamma . \\
\bar{p} \bar{\beta}+\underline{p}(1-\bar{\beta}) & =p .
\end{aligned}
$$

Because the only purpose of assuming that a firm can function without a manager, although less effectively, is to establish reservation levels for firms, and given that we have no interest in the case of a firm that is not run by a (specialized) manager, we need not make any assumptions on whether and how the probabilities of success for a firm without a manager change as a function of the aggregate state.

Managers of both types maximize expected utility of wage payments. We denote their Bernoulli utility function by $U(w)$. For the sake of simplicity we study a situation in which (at most) one equilibrium exists and is interior. For this purpose we assume that $U($.$) is twice continuously differentiable, U^{\prime}()>$.0 , $U^{\prime \prime}(w)<0$, and that the Inada conditions hold, $\lim _{w \rightarrow 0^{+}} U^{\prime}(w)=+\infty, \lim _{w \rightarrow+\infty} U^{\prime}(w)=0$.

After managers learn their types, firms offer contracts to managers. A contract specifies that if the manager accepts it, he will receive a nonnegative payment from the firm for each subsequent public history of the game. Given that a contract offered by a firm to a manager conditions the manager's salary on the public history of the game following acceptance, a contract has to specify a payment for every $\sigma=(P, \Pi) \in\{F, S\} \times\{\underline{\Pi}, \bar{\Pi}\}$, where $P \in\{F, S\}$, denotes the realization of the investment project and $\Pi \in\{\underline{\Pi}, \bar{\Pi}\}$, denotes the realization of the aggregate state. To simplify notation we will denote a contract by

$$
w=\left(\underline{w}_{F}, \underline{w}_{S}, \bar{w}_{F}, \bar{w}_{S}\right) \in \mathbb{R}_{+}^{4}
$$

where $\underline{w}_{P}$ (respectively, $\bar{w}_{P}$ ) denotes the nonnegative payment to the manager when the outcome of the investment process is $P \in\{F, S\}$ and when $\Pi=\underline{\Pi}$ (respectively, when $\Pi=\bar{\Pi}$ ).

The informational structure described above portrays a situation in which both individual and aggregate realizations convey information on the manager's likely behavior and in which shareholders may find it optimal to make managerial compensation dependent on both individual and aggregate results. To avoid unnecessary complications we assume that the aggregate state is directly observable. This means that we ignore the straightforward statistical problem of inferring the likely aggregate state from industry realizations and we concentrate on what firms may infer about a manager's likely behavior from the aggregate state and the implications that this may have on managerial compensation.

We assume that every manager is offered a finite set of contracts $w \in \mathbb{R}_{+}^{4}$ by each of two firms and chooses one contract (if any) from them. All our results generalize to the case in which the measure of the set of managers is lower than the measure of the set of firms and firms are allowed to make offers to all managers.

In the following we summarize the extensive form of the game.

- Nature chooses the type of each manager. Managers' types are i.i.d., and their realizations are $G$ with probability $\mu$ and $B$ with probability $1-\mu$.

- Each manager privately observes his type, $\tau$.

- Without observing nature's choices, each of the two firms competing for a given manager offers him a set of contracts, each of them of the form

$$
w=\left(\underline{w}_{F}, \underline{w}_{S}, \bar{w}_{F}, \bar{w}_{S}\right) \in \mathbb{R}_{+}^{4} .
$$

- The manager either accepts an offer or rejects them all.

- If the manager rejects all offers, he and the firms receive reservation utilities (respectively, 0 and $\widetilde{\pi})$.

- If the manager accepts an offer, he is hired. The firm whose offers were not accepted receives its reservation utility.

- Nature chooses 
- The aggregate state $\underline{\Pi}$ with probability $\underline{\beta}$ and $\bar{\Pi}$ with probability $\bar{\beta}$.

- The realization of revenue (gross of executive compensation) for each firm that has hired a manager, conditional on the aggregate state and on the type of the manager.

* If the aggregate state is $\underline{\Pi}$ and the manager is good, the realization will be $S$ with probability $\underline{p}+\underline{\gamma}$.

* If the aggregate state is $\underline{\Pi}$ and the manager is bad, the realization will be $S$ with probability p.

* If the aggregate state is $\bar{\Pi}$ and the manager is good, the realization will be $S$ with probability $\bar{p}+\bar{\gamma}$

* If the aggregate state is $\bar{\Pi}$ and the manager is bad, the realization will be $S$ with probability $\bar{p}$.

- The realization of the investment project is publicly observed, $P \in\{F, S\}$.

- The aggregate state $\Pi \in\{\underline{\Pi}, \bar{\Pi}\}$ is publicly observed.

- The firm pays the manager salary $\underline{w}_{P}$ or $\bar{w}_{P}$ when the public signal was $\underline{\Pi}$ or $\bar{\Pi}$, respectively.

Given that no additional use of notation will be made, we choose not to provide a full description of strategies and strategy spaces. Also, for notational convenience, we will occasionally omit arguments whenever this cannot cause any confusion.

The equilibrium concept we use is subgame perfect Nash equilibrium.

\section{Equilibrium}

Suppose that a manager has accepted a contract $w=\left(\underline{w}_{F}, \underline{w}_{S}, \bar{w}_{F}, \bar{w}_{S}\right) \in \mathbb{R}_{+}^{4}$. We denote by $\underline{\alpha}_{P}^{\tau}$ the probability that the final public outcome is $(P, \underline{\Pi}), P \in\{F, S\}$, conditional on manager's type being $\tau$. Similarly, we will denote by $\bar{\alpha}_{P}^{\tau}$ the probability that the final public outcome is $(P, \bar{\Pi}), P \in\{F, S\}$ conditional on manager's type being $\tau$. The expected utility deriving from contract $w=\left(\underline{w}_{F}, \underline{w}_{S}, \bar{w}_{F}, \bar{w}_{S}\right) \in$ $\mathbb{R}_{+}^{4}$ for a manager of type $\tau=G, B$ is therefore

$$
V^{\tau}(w)=\underline{\alpha}_{F}^{\tau} U\left(\underline{w}_{F}\right)+\underline{\alpha}_{S}^{\tau} U\left(\underline{w}_{S}\right)+\bar{\alpha}_{F}^{\tau} U\left(\bar{w}_{F}\right)+\bar{\alpha}_{S}^{\tau} U\left(\bar{w}_{S}\right) .
$$

Marginal rates of substitution between salary payments in any two states of the world for a manager of type $\tau=G, B$ are defined in the obvious way. For instance the marginal rate of substitution of $\underline{w}_{S}$ for $\bar{w}_{S}$ is:

$$
M R S_{\underline{w}_{S}, \bar{w}_{S}}^{\tau}(w)=-\frac{\frac{\partial V^{\tau}(w)}{\partial \underline{w}_{S}}}{\frac{\partial V^{\tau}(w)}{\partial \bar{w}_{S}}}=-\frac{\underline{\alpha}_{S}^{\tau}}{\bar{\alpha}_{S}^{\tau}} \frac{U^{\prime}\left(\underline{w}_{S}\right)}{U^{\prime}\left(\bar{w}_{S}\right)}
$$

We now depict the indifference curves of the good and the bad manager in the planes $\left(\underline{w}_{F}, \bar{w}_{F}\right)$ and $\left(\underline{w}_{S}, \bar{w}_{S}\right)$. Simple calculations show that for all $w=\left(\underline{w}_{F}, \underline{w}_{S}, \bar{w}_{F}, \bar{w}_{S}\right) \in \mathbb{R}_{+}^{4}$ and for all $(\underline{p}, \bar{p}, \underline{\gamma}, \bar{\gamma})$ such that $\bar{p}>\underline{p}$ and such that $\bar{p}+\bar{\gamma}>\underline{p}+\underline{\gamma}^{12}$

$$
M R S_{\underline{w}_{F}, \bar{w}_{F}}^{G}(w)>M R S_{\underline{w}_{F}, \bar{w}_{F}}^{B}(w) \Leftrightarrow \frac{\bar{\gamma}}{\underline{\gamma}}<\frac{1-\bar{p}}{1-\underline{p}}
$$

and

$$
M R S_{\underline{w}_{S}, \bar{w}_{S}}^{G}(w)>M R S_{\underline{w}_{S}, \bar{w}_{S}}^{B}(w) \Leftrightarrow \frac{\bar{\gamma}}{\underline{\gamma}}>\frac{\bar{p}}{\bar{p}}
$$

Note that

$$
\frac{\bar{\gamma}}{\underline{\gamma}}<\frac{1-\bar{p}}{1-\underline{p}}
$$

\footnotetext{
${ }^{12}$ Notice that we don't necessarily impose that $\bar{\gamma}>\underline{\gamma}$.
} 
is equivalent to

$$
\frac{\operatorname{Pr}(F \mid \tau=G, \Pi=\underline{\Pi})}{\operatorname{Pr}(F \mid \tau=B, \Pi=\underline{\Pi})}<\frac{\operatorname{Pr}(F \mid \tau=G, \Pi=\bar{\Pi})}{\operatorname{Pr}(F \mid \tau=B, \Pi=\bar{\Pi})},
$$

which means that the failure is relatively more likely to derive from the good manager rather than the bad in state $\bar{\Pi}$ than in state $\underline{\Pi}$. Note that a bad manager has higher probability of failure in either aggregate state, but condition (4) requires that the relative likelihood of failure deriving from the good rather than the bad manager is higher in the favorable rather than in the unfavorable aggregate state.

In similar way we have that

$$
\frac{\bar{\gamma}}{\underline{\gamma}}>\frac{\bar{p}}{\bar{p}}
$$

is equivalent to

$$
\frac{\operatorname{Pr}(S \mid \tau=G, \Pi=\bar{\Pi})}{\operatorname{Pr}(S \mid \tau=B, \Pi=\bar{\Pi})}>\frac{\operatorname{Pr}(S \mid \tau=G, \Pi=\underline{\Pi})}{\operatorname{Pr}(S \mid \tau=B, \Pi=\underline{\Pi})} .
$$

which means that success is relatively more likely to derive from the good manager rather than the bad one in state $\bar{\Pi}$ than in state $\underline{\Pi}$. As before, note that a bad manager has lower probability of success in either aggregate state, but condition (6) is satisfied when the relative likelihood of success deriving from the good rather than the bad manager is higher in the favorable rather than in the unfavorable aggregate state. cases:

Notice that because $\frac{1-\bar{p}}{1-\underline{p}}<\frac{\bar{p}}{\underline{p}}$, at most one of (3) and (5) can hold and that we have the following three

- Case (i): $\frac{1-\bar{p}}{1-\underline{p}}<\frac{\bar{p}}{\underline{p}}<\frac{\bar{\gamma}}{\underline{\gamma}}$, only (5) holds;

- Case (ii): $\frac{1-\bar{p}}{1-\underline{p}}<\frac{\bar{\gamma}}{\underline{\gamma}}<\frac{\bar{p}}{\underline{p}}$, neither (3) nor (5) hold;

- Case (iii): $\frac{\bar{\gamma}}{\underline{\gamma}}<\frac{1-\bar{p}}{1-\underline{p}}<\frac{\bar{p}}{\underline{p}}$, only (3) holds

Consider case (i). By (1) we have

$$
M R S_{\underline{w}_{F}, \bar{w}_{F}}^{G}(w)<M R S_{\underline{w}_{F}, \bar{w}_{F}}^{B}(w)
$$

and by (2) we have

$$
M R S_{\underline{\underline{w}}_{S}, \bar{w}_{S}}^{G}(w)>M R S_{\underline{w}_{S}, \bar{w}_{S}}^{B}(w) .
$$

Figure 1 depicts the indifference curves of the good and the bad manager in the planes $\left(\underline{w}_{F}, \bar{w}_{F}\right)$ and $\left(\underline{w}_{S}, \bar{w}_{S}\right)$ for a given contract $w=\left(\underline{w}_{F}, \underline{w}_{S}, \bar{w}_{F}, \bar{w}_{S}\right)$ in case (i). In such a case (7) and (8) imply that the (absolute) slope of the indifference curve of the good manager in the plane $\left(\underline{w}_{F}, \bar{w}_{F}\right)$ is higher than that of the bad manager (Figure 1(a)) and that the (absolute) slope of the indifference curve of the good manager in the plane $\left(\underline{w}_{S}, \bar{w}_{S}\right)$ is lower than that of the bad manager (Figure 1(b)). In case (iii) the indifference curves of types $G$ and $B$ in both figures would be inverted. In case (ii) the (absolute) slopes of the indifference curves for the good manager would be higher than the corresponding sloped for the bad manager in both planes.

For the purposes of presentation we prefer to focus our attention on one of the cases above. Recall that the goal of the paper is to show that it is possible to have equilibria in which managers accept contracts that are not monotonically decreasing in the aggregate state and therefore in aggregate performance. For this reason in the rest of the paper we will focus our attention on case (i) in which such property holds. We will then discuss how results are modified in cases (ii) and (iii).

The indifference curves in Figure 1(a) clarify that, conditional on the investment project being a failure, the good type is more willing than the bad type to trade compensation when the aggregate state is unfavorable against compensation when the aggregate state is favorable. Similarly, the indifference curves in Figure 1(b) illustrate that, conditional on the investment project being successful, the good type is more willing than the bad type to trade compensation when the aggregate state is favorable against compensation when the aggregate state is unfavorable.

We now want to define and characterize a pair of contracts $\left(w^{R S W-B}, w^{R S W-G}\right)$ that satisfy the following conditions: 
1. Type $B$ does not prefer $w^{R S W-G}$ to $w^{R S W-B}$;

2. Type $G$ does not prefer $w^{R S W-B}$ to $w^{R S W-G}$;

3. A firm that offers $w^{R S W-B}$ at least breaks even when $w^{R S W-B}$ is accepted only by type $B$.

4. A firm that offers $w^{R S W-G}$ at least breaks even when $w^{R S W-G}$ is accepted only by type $G$.

5. No pair of contracts exists that satisfies the previous conditions and is such that no type of manager is worse off and at least one type is strictly better off.

We refer to $\left(w^{R S W-B}, w^{R S W-G}\right)$ as the Rothschild-Stiglitz-Wilson (RSW) contracts in reference to the work of Rothschild and Stiglitz (1976) and Wilson (1977) on insurance markets with adverse selection. ${ }^{13}$ We define the following RSW-best responses:

\section{DEFINITION 1}

$$
\begin{aligned}
w^{R S W-B}\left(w^{G}\right) & =\arg \max _{w \in \mathbb{R}_{+}^{4}} V^{B}(w) \\
\text { s.t. } E[\pi-w \mid B] & \geq \tilde{\pi} \\
V^{G}\left(w^{G}\right) & \geq V^{G}(w) . \\
w^{R S W-G}\left(w^{B}\right) & =\arg \max _{w \in \mathbb{R}_{+}^{4}} V^{G}(w) \\
\text { s.t. } E[\pi-w \mid G] & \geq \tilde{\pi} \\
V^{B}\left(w^{B}\right) & \geq V^{B}(w) .
\end{aligned}
$$

In words, for a given $w^{G}, w^{R S W-B}\left(w^{G}\right)$ is the contract that maximizes the expected payoff to a bad manager subject to the following two conditions (i) the expected payoff to a firm that offers this contract and whose offer is accepted only by the bad manager is no lower than the firm's reservation level and (ii) the good manager does not prefer this contract to $w^{G}$. Similarly, for a given $w^{B}, w^{R S W-G}\left(w^{B}\right)$ is the contract that maximizes the expected payoff to a good manager subject to the following three conditions (i) the expected payoff to a firm that offers this contract and whose offer is accepted only by the good manager is no lower than the firm's reservation level and (ii) the bad manager does not prefer this contract to $w^{B}$.

We can now define the Rothschild-Stiglitz-Wilson pair of contracts.

Definition 2 A pair of contracts is Rothschild-Stiglitz-Wilson, $\left(w^{R S W-B}, w^{R S W-G}\right)$, if and only if

$$
\begin{aligned}
w^{R S W-B} & =w^{R S W-B}\left(w^{R S W-G}\right) \\
w^{R S W-G} & =w^{R S W-G}\left(w^{R S W-B}\right)
\end{aligned}
$$

Notice that the break-even constraints in Definition 1 imply that $w^{R S W-B} \neq w^{R S W-G}$.

The following Proposition provides a characterization of RSW pair of contracts in case (i).

Proposition 1 In case (i) there exists a unique pair of contracts $R S W$ and it is such that:

1. A bad manager receives a constant wage

$$
\underline{w}_{S}^{R S W-B}=\underline{w}_{F}^{R S W-B}=\bar{w}_{S}^{R S W-B}=\bar{w}_{F}^{R S W-B} ;
$$

2. A good manager receives a wage that is

- Increasing in own performance

$$
\begin{aligned}
& \underline{w}_{S}^{R S W-G} \geq \underline{w}_{F}^{R S W-G} \\
& \bar{w}_{S}^{R S W-G} \geq \bar{w}_{F}^{R S W-G} ;
\end{aligned}
$$

${ }^{13}$ We follow standard terminology. See for instance Maskin and Tirole (1992). 
- Decreasing in aggregate performance, if individual performance is low

$$
\underline{w}_{F}^{R S W-G} \geq \bar{w}_{F}^{R S W-G} ;
$$

- Increasing in aggregate performance, if individual performance is high

$$
\bar{w}_{S}^{R S W-G} \geq \underline{w}_{S}^{R S W-G} .
$$

Proof: Appendix.

Proposition 1 establishes that the contract preferred by the bad manager, $w^{R S W-B}$, is a constant contract that insulates him from any source of risk. The contract preferred by the good manager, $w^{R S W-G}$, instead exposes him to risk in both own and aggregate performance. In particular compensation is (weakly) increasing in own performance, but is not monotonically decreasing in aggregate performance. When individual performance is low (i.e., with failure) compensation is decreasing in aggregate performance. But when individual performance is high (i.e., with success) compensation is increasing in aggregate performance, in contrast to the form of RPE that is normally taken for granted.

Similar characterizations obtain for the other two cases. In case (ii) compensation for the good manager will be monotonically decreasing in the aggregate performance. In case (iii), compensation for the good manager will be decreasing in aggregate performance when individual performance is high, but increasing in aggregate performance when individual performance is low.

The next proposition characterizes the subgame perfect Nash equilibrium.

Proposition 2 In the path of a subgame perfect Nash equilibrium:

1. The bad manager accepts contract

$$
w^{B}=w^{R S W-B} ;
$$

2. The good manager accepts contract

$$
w^{G}=w^{R S W-G} .
$$

Proof: Appendix.

The proof of Proposition 2 follows standard arguments. It first establishes that in equilibrium firms earn zero profits on top of their reservation utility of $\widetilde{\pi}$. It then rules out the possibility of "pooling" equilibria in which both types of managers accept the same contract by showing that it is always possible to deviate and make an offer that would be accepted only by the good manager and which earns the firm positive profits. Finally, it shows that all "separating" offers different from the RSW contracts are also vulnerable to the same type of deviation. This shows that if a subgame perfect Nash equilibrium exists, it has to be such that the two types of managers accept the RSW contracts. These results are reminiscent of the results on insurance with adverse selection of Rothschild and Stiglitz (1976) and Wilson (1977).

Part 2 states that if a subgame perfect Nash equilibriums exists, the contract accepted by the good manager is such that his compensation is higher in states with a higher likelihood of the good manager relative to the bad. As in the principal-agent literature, this result evokes a statistical interpretation, but no actual statistical inference is drawn in equilibrium given that, once a manager has accepted contract $w^{R S W-G}$, he is known to be good with probability 1 .

To understand Proposition 2 consider again case (i). In this case, the likelihood of individual success and a favorable aggregate state relative to individual success and an unfavorable aggregate state is higher for a good manager than a bad one. This implies that a good manager is more willing than a bad manager to trade compensation in the event of individual success and a favorable aggregate state against compensation in the event of individual success and an unfavorable aggregate state. This means that competition forces firms to offer a contract for the good manager with higher compensation in the first event than in the second.

The previous argument can be clarified by Figure 2. Suppose that, contrary to the claim of Proposition $2, \bar{w}_{S}^{R S W-G}<\underline{w}_{S}^{R S W-G}$, as, for instance, in point $W 2$ in Figure 2 . Given that, when $\underline{w}_{S}=\bar{w}_{S}$,

$$
M R S_{\underline{w}_{S}, \bar{w}_{S}}^{G}(w)=-\frac{\operatorname{Pr}(S, \underline{\Pi} \mid G)}{\operatorname{Pr}(S, \bar{\Pi} \mid G)},
$$


$\bar{w}_{S}^{R S W-G}<\underline{w}_{S}^{R S W-G}$ implies that

$$
M R S_{\underline{w}_{S}, \bar{w}_{S}}^{G}\left(w^{R S W-G}\right)>-\frac{\operatorname{Pr}(S, \underline{\Pi} \mid G)}{\operatorname{Pr}(S, \bar{\Pi} \mid G)},
$$

i.e., $G G$, the indifference curve of the good manager, is less steep at $w^{R S W-G}$ than $g g$, the set of contracts that have the same expected cost as $w^{R S W-G}$ conditioned on only the good manager accepting it. Consider now a contract $\widehat{w}$ which differs from $w^{R S W-G}$ in that $\left(\underline{w}_{S}^{R S W-G}, \bar{w}_{S}^{R S W-G}\right)$ is replaced by $\left(\underline{w}_{S}^{\prime}, \bar{w}_{S}^{\prime}\right)$ below $g g$, below $B B$, and above $G G$. This contract is strictly better for the good manager, strictly worse for the bad manager and is such that the expected compensation cost, conditional on only the good manager accepting it, is no higher than the expected compensation cost of $w^{R S W-G}$. This means that a profitable deviation exists and rules out that $w^{R S W-G}$ can be such that $\bar{w}_{S}^{R S W-G}<\underline{w}_{S}^{R S W-G}$.

Notice that the same argument does not apply when $\bar{w}_{S}^{R S W-G} \geq \underline{w}_{S}^{R S W} \underline{-G}$, as for instance in point $W 1$ in Figure 2. In this case, $g g$, the set of contracts that have the same expected cost as $w^{R S W-G}$ conditioned on only the good manager accepting it, is less steep than $G G$, the indifference curve of the good manager. Given that $G G$ is less steep than $B B$, the set of contracts that are more profitable than $W 1$ conditional on only the good manager accepting it, and above $G G$ are also above $B B$. In other words, the contracts that lie above $G G$ and below $g g$, also lie above $B B$.

In a similar way, the likelihood of individual failure and a favorable aggregate state relative to individual failure and an unfavorable aggregate state is lower for a good manager than a bad one. This implies that a good manager is more willing than a bad manager to trade compensation in the event of individual failure and an unfavorable aggregate state against compensation in the event of individual failure and a favorable aggregate state. This means that competition forces firms to offer a contract for the good manager with higher compensation in the first event than in the second.

Note that this result does not depend on renegotiation and managers' outside opportunities being correlated with the market, because we assume that managers have commitment ability when they accept a contract. Instead, the result derives from the fact that firms' offers have to exhaust the possible gains deriving from offers that separate good managers from bad ones promising different payments in different states of nature.

It is important to clarify that Proposition 2 does not establish existence of a subgame perfect Nash equilibrium, because it shows that profitable deviations that attract only the good manager exist for all contracts different from the RSW contracts. When the RSW contracts are offered, such a deviation is not profitable, but other deviations may be, in which case no subgame perfect Nash equilibrium exists. To see this, notice first that no profitable deviation may exist that is such that only the bad manager accepts a different contract, because $w^{R S W-B}$ is the contract that the bad manager prefers among all contracts that break even. This means that if a contract is offered that the bad manager strictly prefers to $w^{R S W-B}$, it has to give negative expected profit. But two other types of deviations may be profitable:

1. A deviation that is such that both types accept the same contract. In this case the firm makes a positive profit if the manager is good and a negative profit if the manager is bad.

2. A deviation that is such that each of the two types accepts a different contract. In this case the deviation has to be such that the firm makes a positive profit if the manager is good and a negative profit if the manager is bad. ${ }^{14}$

While it is impossible to guarantee that such deviations are in general unprofitable, a sufficient condition for that to happen is that the probability of the manager being good is not too high. Note that the possibility that an equilibrium does not exist for certain parameter constellations is pervasive in models of contracting with adverse selection and has been the object of careful analysis. We do not want to review the literature on the issue, but we want to mention that under appropriate modifications of the extensive form of the game, equilibria exist in which the main results of this paper hold.

\footnotetext{
${ }^{14} \mathrm{~A}$ deviation that is such that each of the two types accepts a different contract and such that the firm makes a negative profit if the manager is good and a positive profit if the manager is bad is dominated by a deviation in which only the bad manager accepts a different contract and this type of deviation has already been argued to be unprofitable.
} 
Maskin and Tirole (1992) have analyzed a situation in which the informed party (the manager in our case) offers a set of contracts to the uninformed party (the firm); the latter may accept the set or reject it; if the uninformed party accepts the set of contracts, the informed party then chooses one contract from this set. With this extensive form, the RSW allocation described in Proposition 2 would be the unique equilibrium outcome.

Hellwig (1987) modifies the extensive form by introducing an extra stage in which after the informed party has accepted a contract, the uninformed party may withdraw the contract (if it believes that it will lead to a loss). If we also introduced an additional stage in which firms can withdraw offers that have been accepted, an equilibrium would always exist. In particular, if an equilibrium does not exist in which the managers accept the RSW contracts, an equilibrium exists in which both types of managers accept the same contract. The contract accepted in this equilibrium would be the contract that the good manager most prefers among all contract that break even when accepted by both types. But as for the case of the RSW contract for the good type, in case (i), the contract accepted by both types would be decreasing in the aggregate state when own performance is low and increasing in the aggregate state when own performance is high.

\section{Discussion of THE RESUlts}

\subsection{When does the described technology arise?}

The purpose of this subsection is to show that the assumptions on the joint probability distribution over own and aggregate performance hold in a simple, unsophisticated setting. Suppose that each firm has two investment projects available, $I$ and $I I$. Each project, if undertaken, has two possible realizations, success, with revenue $r=s>0$ and failure, with revenue $r=0$. The prior probability of project $I$ resulting in success is $p$. The prior probability that project $I I$ results in success is $q$. Assume that $p>q$, i.e., project $I$ is ex-ante efficient, and that $q>0$, i.e., the expected revenue from each project is strictly positive ${ }^{15}$. Assume that firms' reservation level, $\tilde{\pi}$, is strictly lower than $q s$, the expected revenue with the ex-ante inferior project.

An aggregate state of nature $\Pi \in\{\underline{\Pi}, \bar{\Pi}\}$ determines the probability of success of investment project $I$ for each individual firm. In the favorable aggregate state $\bar{\Pi}$ the probability of success is $\bar{p}>p$ and in the unfavorable aggregate state $\underline{\Pi}$ the probability of success is $\underline{p}<p$. Recalling that the probability of state $\bar{\Pi}$ is $\bar{\beta}$ and the probability of state $\underline{\Pi}$ is $\underline{\beta}=1-\bar{\beta}$ we have

$$
\bar{p} \bar{\beta}+\underline{p}(1-\bar{\beta})=p .
$$

In a similar way, the aggregate state of nature $\Pi \in\{\underline{\Pi}, \bar{\Pi}\}$ determines the probability of success of individual firms' investment project $I I$. In the favorable aggregate state $\bar{\Pi}$ the probability of success is $\bar{q}>q$ and in the unfavorable aggregate state $\underline{\Pi}$ the probability of success is $\underline{q}<q$. As before, we have

$$
\bar{q} \bar{\beta}+\underline{q}(1-\bar{\beta})=q
$$

Managers have innate abilities to forecast the realization of some projects. For simplicity we assume that only two types of managers exist, good and bad, $\tau \in\{G, B\}$. When a good manager is employed by a firm, he is able to forecast the realization of investment project $I$, whereas a bad manager is unable to improve his forecast beyond the prior probabilities of success. For the sake of simplicity we assume that neither good nor bad managers are able to make any forecast about the realization of project $I I$. Given that project $I$ is ex-ante superior to project $I I$, this assumption could be justified if, for instance, the manager could devote a limited amount of time to the analysis of investment projects and it were optimal for him to dedicate it to project $I$.

Each manager knows his own type, but it is common knowledge that firms believe that he is good with probability $\mu$ and bad with probability $1-\mu$. When analyzing project $I$, a manager receives a signal $\rho \in\{V, L, H\}$. The bad manager receives signal $V$, the void signal, with probability 1 and the good

\footnotetext{
${ }^{15}$ Notice that $q>0$ implies $p>0$.
} 
manager receives signals $L$ or $H$, the low and the high signal, with probabilities $1-p$ and $p$, respectively. The probability of project $I$ having the high return $(s>0)$ conditional on the received signal is

$$
\operatorname{Pr}(r=s \mid \rho, I)=\left\{\begin{array}{ll}
p & \text { if } \rho=V \\
0 & \text { if } \rho=L \\
1 & \text { if } \rho=H
\end{array} .\right.
$$

In other words, while signals $H$ and $L$ ensure, respectively, the success or the failure of investment project $I$, the void signal, $V$, provides no additional information and the conditional probability of success is, therefore, equal to the prior, $p .^{16}$

Our assumption guarantee that it is always efficient to undertake one investment project, be it $I$ or $I I$. We can restrict the manager's action space to $\{I, I I\}$. We assume that the manager's choice of the project is not observable but its ultimate realization is. As before we denote the observable final outcome of the investment project by $P \in\{F, S\}$, where $F$ and $S$ indicate a failure (revenue equal to 0 ) or a success (revenue equal to $s$ ). An investment profile for a manager is a vector $i=\left(i_{V}, i_{L}, i_{H}\right) \in\{I, I I\}^{3}$ where $i_{V}, i_{L}$ and $i_{H}$ denote the decision to invest in project $I$ or $I I$ when the signal received by the manager is respectively $V, L$, or $H$. We denote by $i^{E}=(I, I I, I)$ the efficient investment profile. It is then easy to show that if the manager plays the efficient investment profile, the probabilities of success and failure for the two types of manager are as described before with $\bar{\gamma}=\bar{q}(1-\bar{p})$ and $\underline{\gamma}=\underline{q}(1-\underline{p})$. This means that, for instance, case (i) obtains when

$$
\frac{\bar{q}(1-\bar{p})}{q(1-\underline{p})}>\frac{\bar{p}}{\underline{p}} \Longleftrightarrow \frac{\underline{p}}{\underline{q}(1-\underline{p})}>\frac{\bar{p}}{\bar{q}(1-\bar{p})} .
$$

Notice that the second inequality clarifies that the relative likelihood of success deriving from the good manager rather than the bad is higher in the favorable aggregate state, because, when the manager plays the efficient investment profile, success is relatively less likely to derive form project $I$ rather than $I I$ in state $\bar{\Pi}$ than in state $\underline{\Pi}$ and the manager chooses project $I I$ only when he is good.

Notice also, that the same formulation would give rise to case (ii) when

$$
\frac{\underline{p}}{\underline{q}(1-\underline{p})}<\frac{\bar{p}}{\bar{q}(1-\bar{p})}
$$

and that case (iii) could arise if $\bar{q}<\underline{q}$, i.e., if the aggregate state that has been termed favorable, $\bar{\Pi}$, is favorable for project $I$ but not for project $I I$.

The previous discussion has clarified that when managers make efficient investment decisions, the probability distributions that were postulated in the paper arise. But if managers can choose one investment project or the other, it would of course be necessary to verify that they want to make efficient investment decisions in equilibrium and that the possibility of deviation in the investment decision do not have an impact on the contracts which are accepted in equilibrium and therefore on the equilibrium distributions over salaries and individual and aggregate performance. We have explicitly analyzed this issue in a previous version of this paper and we have found that no change occurs on the contracts accepted in equilibrium and therefore on equilibrium distributions over payoffs.

\subsection{An example}

We now consider the case in which the manager has constant relative risk aversion, $U(c)=\frac{c^{1-\sigma}}{1-\sigma}$, with $\sigma=0.5$. We assume that probabilities of success are $p=0.6, \bar{p}=0.7, \underline{p}=0.5, \bar{q}=0.35, \underline{q}=0.01$, that the favorable and the unfavorable aggregate states are equally likely $\bar{\beta}=\beta=0.5$, that revenue under success is $s=30$, and that firms' reservation level is $\widetilde{\pi}=12$. Notice that these parameter values satisfy the conditions of the model and in particular are such that (5) holds so that $\bar{w}_{S}^{R S W-G}>\underline{w}_{S}^{R S W-G}$.

\footnotetext{
${ }^{16}$ Managers with high ability are often described in the literature as being able to generate high expected return investment projects, i.e., as being able to come up with good ideas. In contrast to this, we refer to managerial ability as the ability to forecast the realization of a given project. All investment projects are drawn from the same distribution, regardless of the manager's ability, but different managers may have different abilities to forecast their realizations.
} 
The purpose of this example is to show that when (5) holds, and, therefore, when $\bar{w}_{S}^{R S W-G}>\underline{w}_{S}^{R S W-G}$, the aggregate relationship between executive compensation and market movements may be positive. This may help explain the apparently disconcerting empirical evidence on RPE that has been discussed in the introduction.

We find that the RSW contracts are

$$
\begin{aligned}
w^{R S W-B} & =\left(\underline{w}_{F}^{R S W-B}, \underline{w}_{S}^{R S W-B}, \bar{w}_{F}^{R S W-B}, \bar{w}_{S}^{R S W-B}\right)=(6,6,6,6) \\
w^{R S W-G} & =\left(\underline{w}_{F}^{R S W-G}, \underline{w}_{S}^{R S W-G}, \bar{w}_{F}^{R S W-G}, \bar{w}_{S}^{R S W-G}\right)=(6.6000,7.0993,0.0024,10.4936) .
\end{aligned}
$$

The bad manager accepts a constant contract that fully insures him. The good manager accepts a contract which gives him compensation which is increasing in own performance, decreasing in industry performance when individual performance is low, but increasing in industry performance when individual performance is high. In other words, the good manager receives higher compensation when firm performance is in line with industry performance.

We now analyze whether the RSW contracts derived above may lead to a positive relationship between executive compensation and aggregate performance. To do this we compute the joint probability distributions over executives' salaries, firms' own profits, and industry profits generated by equilibrium play. We then compute the population best linear predictor of salaries conditioned on firm profits (FP) and industry profits (IP)

$$
E[w \mid \mathrm{FP}, \mathrm{IP}]=\beta_{0}+\beta_{1} \cdot \mathrm{FP}+\beta_{2} \cdot \mathrm{IP}
$$

Notice that the previous specification omits information about the type of the manager but replicates the specifications of most empirical studies on executive compensation. We have repeated the exercise for different values of the prior probability of the manager being good and we have always found the same qualitative results. In Table 1 we report the estimation results for five different values of the probability of being good. In columns 2 to 4 we report the regression coefficients. The results summarized in Table 1, suggest that wages are increasing in own performance (column 3) but they are also increasing in industry performance (column 4).

This result appears as a violation of the shape that is normally taken for granted for RPE but is consistent with the results documented by the empirical literature. In other words our model clarifies that asymmetric information on executive talent and competition in the market for executives can generate a distribution of outcomes that is consistent with existing empirical studies.

\subsection{Extension: $T$ types of managers}

The model we have used so far has made the assumption that only two types of managers exist, good and bad. The purpose of this subsection is to clarify that this assumption is made only for the sake of simplicity and that our results can be obtained with an arbitrary but finite number of types of executives. Here we propose an extension of the model described in section 4.1.

Assume that a manager can be of type $\tau=\{1, \ldots \ldots, T\}$ and that each type $\tau$ gets a signal $\rho \in\{L, H\}$ about the realization of project $I$. Types differ in the informativeness of the signal they receive. In particular, assume that type $\tau$ has probability $\lambda(\tau)$ of receiving a high signal when project $I$ is destined to success and to receive a low signal when project $I$ is doomed to failure and that

$$
\begin{aligned}
\lambda(\tau) & =\operatorname{Pr}(\rho=H \mid r=s, I, \tau)=\operatorname{Pr}(\rho=L \mid r=0, I, \tau)= \\
& =\frac{T-\tau}{T-1} \frac{p(1-q)}{p(1-q)+(1-p) q}+\frac{\tau-1}{T-1}
\end{aligned}
$$

Notice that $\lambda(\tau)$ is increasing in $\tau$, that $\lambda(T)=1$ and that

$$
\lambda(1)=\frac{p(1-q)}{p(1-q)+(1-p) q}>\frac{1}{2} .
$$

This implies that higher types receive more informative signals, that the best type, $T$, is able to perfectly forecast the realization of project $I$ and that the worst possible type, 1 , receives a signal which has positive although limited informativeness about the realization of project $I$. 
The probability of project $I$ having the high return $(s>0)$ conditional on the high signal is

$$
\operatorname{Pr}(r=s \mid \rho=H, I, \tau)=\frac{\lambda(\tau) p}{\lambda(\tau) p+(1-\lambda(\tau))(1-p)}
$$

and the probability of project $I$ having the high return $(s>0)$ conditional on the low signal is

$$
\operatorname{Pr}(r=s \mid \rho=L, I, \tau)=\frac{(1-\lambda(\tau)) p}{(1-\lambda(\tau)) p+\lambda(\tau)(1-p)}
$$

Given that $\lambda(\tau)$ is increasing in $\tau, \operatorname{Pr}(r=s \mid \rho=L, I, \tau)$ is decreasing in $\tau$. Notice also that for the best type $\tau=T$

$$
\operatorname{Pr}(r=s \mid \rho, I, T)= \begin{cases}1 & \text { if } \rho=H \\ 0 & \text { if } \rho=L\end{cases}
$$

and for the worst type $\tau=1$,

$$
\operatorname{Pr}(r=s \mid \rho, I, 1)= \begin{cases}\frac{p^{2}(1-q)}{p^{2}(1-q)+(1-p)^{2} q} & \text { if } \rho=H \\ q & \text { if } \rho=L\end{cases}
$$

Because $\operatorname{Pr}(r=s \mid \rho=L, I, \tau=1)=q$, we have that for all $\tau>1$

$$
\operatorname{Pr}(r=s \mid \rho=L, I, \tau)<q .
$$

From the above it follows that, if executive compensation is increasing in absolute performance (which implies that the manager wants to maximize expected absolute performance) all types of manager prefer to invest in project $I$ if they receive the high signal, $\rho=H$, that all $\tau>1$ prefer to invest in $I I$ if they receive the low signal and that only the worst type $\tau=1$ is indifferent between investing in project $I$ or $I I$ if he receives the low signal. Assume, that when indifferent between project $I$ and $I I$, type $\tau=1$ chooses project $I$, and let $i^{E}$ denote the efficient investment profile that specifies that type $\tau=1$ always invests in project $I$, and that all types $\tau>1$ invest in project $I$ when they receive the high signal, and in project $I I$ when they receive the low signal.

Under the assumptions on the joint distribution of individual and aggregate states made in 3 , straightforward calculations show that for all types $\tau=\{1, \ldots T\}$

$$
\begin{aligned}
& \underline{\alpha}_{S}^{\tau}\left(i^{E}\right)=\underline{\beta}\{\underline{\lambda}(\tau) \underline{p}+\underline{q}[(1-\underline{\lambda}(\tau)) \underline{p}+\underline{\lambda}(\tau)(1-\underline{p})]\} \\
& \bar{\alpha}_{S}^{\tau}\left(i^{E}\right)=\bar{\beta}\{\bar{\lambda}(\tau) \bar{p}+\bar{q}[(1-\bar{\lambda}(\tau)) \bar{p}+\bar{\lambda}(\tau)(1-\bar{p})]\} \\
& \underline{\alpha}_{F}^{\tau}\left(i^{E}\right)=\underline{\beta}\{(1-\underline{\lambda}(\tau))(1-\underline{p})+(1-\underline{q})[(1-\underline{\lambda}(\tau)) \underline{p}+\underline{\lambda}(\tau)(1-\underline{p})]\} \\
& \bar{\alpha}_{F}^{\tau}\left(i^{E}\right)=\bar{\beta}\{(1-\bar{\lambda}(\tau))(1-\bar{p})+(1-\bar{q})[(1-\bar{\lambda}(\tau)) \bar{p}+\bar{\lambda}(\tau)(1-\bar{p})]\} .
\end{aligned}
$$

Tedious calculations show that for all $\tau^{\prime}>\tau$, for all $w=\left(\underline{w}_{F}, \underline{w}_{S}, \bar{w}^{F}, \bar{w}^{S}\right) \in R_{+}^{4}$ and for all $(\underline{p}, \bar{p}, \underline{q}, \bar{q})$ such that $\bar{p}>\underline{p}, \bar{q}>\underline{q}, \bar{p}>\bar{q}$ and $\underline{p}>\underline{q}$

$$
M R S_{\underline{w}_{F}, \bar{w}_{F}}^{\tau^{\prime}}\left(w, i^{E}\right)<M R S_{\underline{w}_{F}, \bar{w}_{F}}^{\tau}\left(w, i^{E}\right)
$$

and that for all $w=\left(\underline{w}_{F}, \underline{w}_{S}, \bar{w}_{F}, \bar{w}_{S}\right) \in \mathbb{R}_{+}^{4}$

$$
\operatorname{sign}\left(M R S_{\underline{w}_{S}, \bar{w}_{S}}^{\tau^{\prime}}(w)-M R S_{\underline{w}_{S}, \bar{w}_{S}}^{\tau}(w)\right)=\operatorname{sign}\left(\frac{\underline{p}}{(1-\underline{p}) \underline{q}}-\frac{\bar{p}}{(1-\bar{p}) \bar{q}}\right) .
$$

Given that conditions (14) and (15) generalize conditions (1) and (2) for the two-type model of section 3 , it is easy to see that the same qualitative results could be obtained in the case of an arbitrary but finite number of types. 


\section{Conclusion}

We present a simple theoretical model that attempts to explain the apparent lack of empirical support for a negative relationship between top executive compensation and market movements. We analyze an adverse selection environment in which contingent executive compensation may be used to sort heterogeneous managers. We find that equilibrium contracts include RPE considerations, but their form may differ from that which is stipulated by the existing literature. In particular we show that good managers accept contracts that may make larger payments when the aggregate state is favorable rather than unfavorable. In other words, we find in a very simple setting that executive compensation is not necessarily decreasing with industry performance. An example shows that this effect may lead to a positive relationship between executive compensation and aggregate performance and that our results may resolve the apparent discrepancy between the empirical and the theoretical literature.

Most of the literature on executive compensation has concentrated on contingent contracts as tools to endow managers with incentives to make appropriate decisions. In this paper we take the opposite viewpoint and analyze a situation in which contingent compensation is used to sort heterogeneous managers. But, as is commonly the case with contracts in asymmetric information environments, similar results could be obtained in a moral hazard setting. It would obviously be important to determine whether executive compensation can be explained better by moral hazard or adverse selection. ${ }^{17}$ But the contribution of our paper is to show that a standard competitive model can explain why executive compensation may be increasing in market movements.

Our focus on adverse selection also suggests ways in which future empirical research may overcome the problems encountered by the empirical research on moral hazard models of executive compensation that was emphasized by Antle and Smith (1986): "A limitation of any method of inferring contract structure from data is that only the payments under equilibrium behavior are realized. Yet an important part of any incentive scheme is the implied consequence of departing from equilibrium behavior" ${ }^{\prime 18}$. This limitation applies to models of moral hazard, because for each observable realization, compensation depends on the likelihood of the equilibrium action relative to the action that makes the incentive compatibility constraint binding. While data can be used to estimate the probability distribution over observable realizations conditional on the equilibrium action, this is impossible for the actions which are not taken in equilibrium and this leaves researchers guessing the form of the optimal compensation scheme.

The same argument does not apply to adverse selection environments. In these settings, the equilibrium compensation of a good manager for a given observable realization depends on the likelihood of the good manager relative to the bad one. This means that if the data makes it possible to distinguish good managers from bad, then it is also possible to estimate the probability distributions over observable realizations for each type of manager. This would ultimately allow the empirical researcher to estimate the likelihood of the good manager relative to the bad one for each observable realization and determine whether observed executive compensation schemes can be explained by adverse selection arguments.

\footnotetext{
${ }^{17}$ Recent research has tried to distinguish between moral hazard and adverse selection in insurance data. See for instance, Abbring, Chiappori, Heckman, and Pinquet (2003) and their references.

${ }^{18}$ Antle and Smith (1986), page 8 (footnote 23 ).
} 


\section{REFERENCES}

[1] Abbring, J.H., P.-A. Chiappori, J.J. Heckman, and J. Pinquet (2003) "Adverse Selection and Moral Hazard in Insurance: Can Dynamic Data Help to Distinguish?" Journal of the European Economic Association, 1(2), 512 - 521 .

[2] Abowd, J.M and D. Kaplan (1999) "Executive Compensation: Six Questions That Need Answering" Journal of Economic Perspectives, 13, 145-168.

[3] Aggarwal, R.K. and A.A. Samwick (1999a) "The Other Side of the Tradeoff: The Impact of Risk on Executive Compensation" Journal of Political Economy, 107, 67-105.

[4] Aggarwal, R.K. and A.A. Samwick (1999b) "Executive compensation, strategic competition, and relative performance evaluation: Theory and evidence" Journal of Finance, LIV, 1999-2043.

[5] Antle, R. and A. Smith (1986) "An empirical Investigation of the Relative Performance Evaluation" Journal of Accounting Research, 24(1), 1-39.

[6] Barro, J.R. and R.J. Barro (1990) "Pay, Performance, and Turnover of Bank CEOs" Journal of Labor Economics, 8(4), 448-481.

[7] Bebchuk, L.A., J.M. Fried and D.I. Walker (2002) "Managerial power and rent extraction in the design of executive compensation" The University of Chicago Law Review, 69, 751-846.

[8] Core and Guay (2002) "When Contracts Require Risk-Averse Executives to Hold Equity", mimeo.

[9] de Swaan, J.C. and N.W.C. Harper (2003) "Getting what you pay for with stock options" The McKinsey Quarterly, 2003-1, Closing Views, 2-5.

[10] Dobbs and Koller (2000) "Stock options aren't enough" The McKinsey Quarterly, 2000-3, 190-192.

[11] Financial Economist Roundtable (2003), "The Controversy Over Executive Compensation", mimeo. Available from http://www.luc.edu/orgs/finroundtable/.

[12] Garvey G.T. and T.T. Milbourn (2003) "Incentive Compensation When Executives Can Hedge the Market: Evidence of Relative Performance Evaluation in the Cross-Section" Journal of Finance, 58(4), 1557-82.

[13] Gibbons, M. and K. Murphy (1990) "Relative performance evaluation for chief executive officers" Industrial and Labour Relations Review, 43, 30-52.

[14] Hall, B. and J. Liebman (1998) "Are CEOs really paid like bureaucrats?" Quarterly Journal of Economics, 113, 653-691.

[15] Hellwig, M. (1987) "Some recent developments in the theory of competition in markets with adverse selection" European Economic Review, 31, 319-325.

[16] Himmelberg, C.P. and R.G. Hubbard (2000) "Incentive Pay and the Market for CEO's: An Analysis of Pay-for-Performance Sensitivity", mimeo., Columbia University.

[17] Holmström, B. (1979) "Moral hazard and observability" Bell Journal of Economics, 10, 74-91.

[18] Holmström, B. (1982) "Moral hazard in teams" Bell Journal of Economics, 13, 324-340.

[19] Holmström, B. and J. Ricart i Costa (1986) "Managerial incentives and capital management" Quarterly Journal of Economics, 101, 835-860.

[20] Janakiraman, S.N., R.A. Lambert, and D.F. Larcker (1992) "An Empirical Investigation of the Relative Performance Evaluation Hypothesis" Journal of Accounting Research, 30(1), 53-69. 
[21] Jensen, M. and K. Murphy (1990) "Performance pay and top-management incentives" Journal of Political Economy, 98, 225-264.

[22] Joh, S.W. (1999) "Strategic Managerial Incentive Compensation in Japan: Relative Performance Evaluation and Product Market Collusion" Review of Economics and Statistics, 81, 303-313.

[23] Kanodia, C., R. Bushman, and J. Dickhaut (1989) "Escalation errors and the sunk cost effect: An explanation based on reputation and information asymmetries" Journal of Accounting Research, 27, 59-77.

[24] Maskin, E. and J. Tirole (1992) "The principal-agent relationship with an informed principal II: Common values" Econométrica, 60, 1-42.

[25] Murphy, K.J. (1999) "Executive Compensation" in O. Ashenfelter and D. Card (eds.) Handbook of Labor Economics, Vol. 3, 2485-2563, North Holland, Amsterdam.

[26] Oyer, P. (2003): "Why do firms use incentives that have no incentive effects?", Journal of Finance, forthcoming.

[27] Prendergast, C. (1999) "The Provision of Incentives in Firms" Journal of Economic Literature, 37, 7-63.

[28] Prendergast, C. (2002) "The Tenuous Trade-off between Risk and Incentives" Journal of Political Economy, 110, 1071-1102.

[29] Ricart i Costa, J. (1989) "On Managerial Contracting with Asymmetric Information" European Economic Review, 33(9), 1805-29.

[30] Rappaport (1999) "New thinking on how to link executive pay with performance", Harvard Business Review, March-April, 91-101.

[31] Rosen, S. (1992) "Contracts and the market for executives" in Werin L. and H. Wijkander (eds.) Contract Economics. Blackwell, Oxford.

[32] Rothschild, M. and J. E. Stiglitz (1976) "Equilibrium in Competitive Insurance Markets: An Essay on the Economics of Perfect Information" Quaterly Journal of Economics, 90(4), September, 629-649.

[33] Salas-Fumas, V. (1992) "Relative performance evaluation of management" International Journal of Industrial Organization", 10, 473-489.

[34] The Economist (2002) "Is Greed Good?" in "Capitalism and Its Troubles. A Survey of International Finance", May 18, 2002, 23-26.

[35] Wilson, C. (1977) "A model of insurance markets with incomplete information" Journal of Economic Theory, 16, 167-207. 


\section{A Appendix}

\section{A.1 Proof of Proposition 1}

Lemma 1 In case (i) there exists a pair of contracts $R S W$ and it is such that:

1. $w^{R S W-B}=((p s-\tilde{\pi}),(p s-\tilde{\pi}),(p s-\tilde{\pi}),(p s-\tilde{\pi}))$

2. $w^{R S W-G} \neq w^{R S W-B}$

3. $w^{R S W-G}$ is such that

$$
\begin{aligned}
& \underline{w}_{S}^{R S W-G} \geq \underline{w}_{F}^{R S W-G} \\
& \bar{w}_{S}^{R S W-G} \geq \bar{w}_{F}^{R S W-G} \\
& \underline{w}_{F}^{R S W-G} \geq \bar{w}_{F}^{R S W-G} \\
& \bar{w}_{S}^{R S W-G} \geq \underline{w}_{S}^{R S W-G}
\end{aligned}
$$

PROOF: The expected profits gross of compensation generated by the two types of manager are

$$
\begin{aligned}
& E[\pi \mid G]=(p+\gamma) s>\widetilde{\pi} \\
& E[\pi \mid B]=p s>\widetilde{\pi}
\end{aligned}
$$

with

$$
E[\pi \mid G]>E[\pi \mid B] .
$$

Given that $U^{\prime}()>$.0 , constraints (9) and (11) have to be satisfied with equality. This implies that $w^{R S W-G}$ cannot be a constant contract, because if it were, type $B$ would prefer it to any contract satisfying (9).

We now want to show that (10) cannot be satisfied with equality. To see this, notice that an upper bound on the utility that type $G$ could get from accepting $w^{R S W-B}$ is the utility he would get by accepting a constant contract satisfying (9) with equality, i.e.,

$$
w=((p s-\widetilde{\pi}),(p s-\widetilde{\pi}),(p s-\widetilde{\pi}),(p s-\widetilde{\pi})) .
$$

Suppose that the good manager accepts this contract and consider the indifference curves of the two types of manager passing through $w$ on the $\left(\underline{w}_{S}, \bar{w}_{S}\right)$ plane as depicted in Figure 3. Notice that given that the good manager generates a higher expected profit, his break-even line, $g g$, lies strictly above $w$. Figure 3 shows that the contracts that differ from $w$ in that $\left(\underline{w}_{S}, \bar{w}_{S}\right)=(p s-\tilde{\pi}, p s-\widetilde{\pi})$ is replaced by a pair strictly above $G G$, strictly below $B B$ and below $g g$ are strictly better for type $G$ and strictly worse for type $B$. This implies that (10) cannot be satisfied with equality.

Given that (10) is slack type $B$ 's risk aversion implies that $w^{R S W-B}$ is constant and satisfies (9) with equality so that

$$
w^{R S W-B}=((p s-\widetilde{\pi}),(p s-\widetilde{\pi}),(p s-\widetilde{\pi}),(p s-\widetilde{\pi}))
$$

as in Part 1. Given that $w^{R S W-G}$ cannot be constant, Part 2 follows.

To prove part 3 notice first that simple calculations show that

$$
\begin{aligned}
& M R S_{\underline{w}_{S}, \bar{w}_{S}}^{G}(w)>M R S_{\underline{w}_{S}, \bar{w}_{S}}^{B}(w) \\
& M R S_{\underline{w}_{F}, \bar{w}_{F}}^{G}(w)<M R S_{\underline{w}_{F}, \bar{w}_{F}}^{B}(w)
\end{aligned}
$$

Given this, to prove part 3, it suffices to show that for any two states $\sigma^{\prime}$ and $\sigma^{\prime \prime}$ :

$$
M R S_{w\left(\sigma^{\prime}\right), w\left(\sigma^{\prime \prime}\right)}^{G}(w)>M R S_{w\left(\sigma^{\prime}\right), w\left(\sigma^{\prime \prime}\right)}^{B}(w)
$$

implies that

$$
w^{R S W-G}\left(\sigma^{\prime \prime}\right) \geq w^{R S W-G}\left(\sigma^{\prime}\right)
$$


and

$$
M R S_{w\left(\sigma^{\prime}\right), w\left(\sigma^{\prime \prime}\right)}^{G}(w)<M R S_{w\left(\sigma^{\prime}\right), w\left(\sigma^{\prime \prime}\right)}^{B}(w)
$$

implies that

$$
w^{R S W-G}\left(\sigma^{\prime \prime}\right) \leq w^{R S W-G}\left(\sigma^{\prime}\right) .
$$

Contrary to (17) suppose that in equilibrium $w^{R S W-G}\left(\sigma^{\prime \prime}\right)<w^{R S W-G}\left(\sigma^{\prime}\right)$, such as for instance $W 2$ in Figure 4. Given that

$$
M R S_{w\left(\sigma^{\prime}\right), w\left(\sigma^{\prime \prime}\right)}^{G}(w)=-\frac{\operatorname{Pr}\left(\sigma^{\prime} \mid G\right)}{\operatorname{Pr}\left(\sigma^{\prime \prime} \mid G\right)}
$$

when $w\left(\sigma^{\prime \prime}\right)=w\left(\sigma^{\prime}\right), w^{R S W-G}\left(\sigma^{\prime \prime}\right)<w^{R S W-G}\left(\sigma^{\prime}\right)$ implies that

$$
M R S_{w\left(\sigma^{\prime}\right), w\left(\sigma^{\prime \prime}\right)}^{G}\left(w^{*}\right)>-\frac{\operatorname{Pr}\left(\sigma^{\prime} \mid G\right)}{\operatorname{Pr}\left(\sigma^{\prime \prime} \mid G\right)}
$$

i.e., $G G$, the indifference curve of the good manager, is less steep at $w^{R S W-G}$ than $g g$, the set of contracts that have the same expected cost as $w^{R S W-G}$ conditioned on only the good manager accepting it. Consider now a contract $\widehat{w}$ which differs from $w^{R S W-G}$ in that $\left(w^{R S W-G}\left(\sigma^{\prime}\right), w^{R S W-G}\left(\sigma^{\prime \prime}\right)\right)$ is replaced by $\left(\widehat{w}\left(\sigma^{\prime}\right), \widehat{w}\left(\sigma^{\prime \prime}\right)\right)$ below $g g$, below $B B$ and above $G G$. This contract is strictly better for the good manager and strictly worse for the bad manager and is such that the expected compensation cost, conditional on only the good manager accepting it, is no higher than the expected compensation cost of $w^{*}$. This implies that contract $\widehat{w}$ gives a higher expected utility to the good manager while satisfying (11) and (12) a contradiction to the hypothesis that $w^{R S W-G}$ could be such that $w^{R S W-G}\left(\sigma^{\prime \prime}\right)<w^{R S W-G}\left(\sigma^{\prime}\right)$.

Notice that the same argument does not apply when $w^{R S W-G}\left(\sigma^{\prime \prime}\right) \geq w^{R S W-G}\left(\sigma^{\prime}\right)$, such as for instance point $W 1$ in Figure 4. In this case, $g g$, the set of contracts that have the same expected cost as $w^{G}$ conditioned on only the good manager accepting it, is less steep than $G G$, the indifference curve of the good manager. Given that $G G$ is less steep than $B B$, the set of contracts that are more profitable than $W 1$ conditional on only the good manager accepting it, and above $G G$ are also above $B B$. In other words, the contracts that lie above $G G$ and below $g g$, such as contract $\left(\widetilde{w}\left(\sigma^{\prime}\right), \widetilde{w}\left(\sigma^{\prime \prime}\right)\right)$, also lie above $B B$. This implies that this contract would violate (12).

Part (18): Similar arguments apply to this case. We will not repeat the full argument, but inspection of Figure 5 should clarify that when $M R S_{w\left(\sigma^{\prime}\right), w\left(\sigma^{\prime \prime}\right)}^{G}(w)<M R S_{w\left(\sigma^{\prime}\right), w\left(\sigma^{\prime \prime}\right)}^{B}(w), w^{R S W-G}$ cannot be like $W 3$ and can be like $W 4$. Suppose first that $w^{R S W-G}$ is such $w^{R S W-G}\left(\sigma^{\prime}\right)<w^{R S W-G}\left(\sigma^{\prime \prime}\right)$, as in point $W 3$ in Figure 5. In this case a contract $\widehat{w}$ that differs from $w^{R S W-G}$ in that $\left(w^{R S W-G}\left(\sigma^{\prime}\right), w^{R S W-G}\left(\sigma^{\prime \prime}\right)\right)$ is replaced by $\left(\widehat{w}\left(\sigma^{\prime}\right), \widehat{w}\left(\sigma^{\prime \prime}\right)\right)$, that lies below $g g$, below $B B$ and above $G G$ would improve upon $w^{R S W-G}$ for type $G$ while satisfying (11) and (12).

Suppose instead that $w^{R S W-G}$ is such $w^{R S W-G}\left(\sigma^{\prime}\right) \geq w^{R S W-G}\left(\sigma^{\prime \prime}\right)$, as in point $W 4$ in Figure 5 . Consider a contract $\widetilde{w}$ that differs from $w^{R S W-G}$ in that $\left(w^{R S W-G}\left(\sigma^{\prime}\right), w^{R S W-G}\left(\sigma^{\prime \prime}\right)\right)$ is replaced by $\left(\widetilde{w}\left(\sigma^{\prime}\right), \widetilde{w}\left(\sigma^{\prime \prime}\right)\right)$, that lies below $g g$ and above $G G$. Given that $G G$ is steeper than $B B$, however, all contracts that lie on or below $g g$ and above $G G$, such as $\left(\widetilde{w}\left(\sigma^{\prime}\right), \widetilde{w}\left(\sigma^{\prime \prime}\right)\right)$, also lie above $B B$ and therefore violate (12).

\section{A.2 Proof of Proposition 2}

We prove Proposition 2 through a sequence of Lemmas.

LEMma 2 In a SPNE firms' expected profits are $\tilde{\pi}$.

Proof: Immediate from a standard Bertrand pricing argument.

LEMma 3 No SPNE exists in which both types accept the same contract.

Proof: Contrary to the claim suppose that there is a SPNE in which both types of managers accept a given contract $w^{*}$. By Lemma 2, if this contract is accepted in equilibrium by both types of managers, 
the payoff to a firm offering it is $\widetilde{\pi}$. Without loss of generality assume that the manager accepts such a contract offered by firm 1 .

Notice that because the probability distributions over final outcomes depend on the manager's type, there has to exist a pair of states $\left(\sigma^{\prime}, \sigma^{\prime \prime}\right)$ such that $M R S_{w\left(\sigma^{\prime}\right), w\left(\sigma^{\prime \prime}\right)}^{\tau}\left(w^{*}\right) \neq M R S_{w\left(\sigma^{\prime}\right), w\left(\sigma^{\prime \prime}\right)}^{\tau^{\prime}}\left(w^{*}\right)$. In the following we will focus without loss of generality on two states, $\sigma^{\prime}$ and $\sigma^{\prime \prime}$ such that $M R S_{w\left(\sigma^{\prime}\right), w\left(\sigma^{\prime \prime}\right)}^{\tau}\left(w^{*}\right)<$ $M R S_{w\left(\sigma^{\prime}\right), w\left(\sigma^{\prime \prime}\right)}^{\tau^{\prime}}\left(w^{*}\right)$.

Consider the following 3 cases:

1. The expected profit to a firm whose offer $w^{*}$ is accepted by type $\tau$ is $\pi_{\tau}>\widetilde{\pi}$.

Consider Figure 6, depicting $T T$ and $T^{\prime} T^{\prime}$, the indifference curves for types $\tau$ and $\tau^{\prime}$ passing through $\left(w^{*}\left(\sigma^{\prime}\right), w^{*}\left(\sigma^{\prime \prime}\right)\right)$ and $\tau \tau$, the set of contracts differing from $w^{*}$ only in that $\left(w^{*}\left(\sigma^{\prime}\right), w^{*}\left(\sigma^{\prime \prime}\right)\right)$ is replaced by $\left(w\left(\sigma^{\prime}\right), w\left(\sigma^{\prime \prime}\right)\right)$ and that conditional on being accepted only by type $\tau$ have the same expected profit as $w^{*}$ when this is accepted by both types, i.e., $\widetilde{\pi}$. Notice that given that $\pi_{\tau}>\widetilde{\pi}$, line $\tau \tau$ lies strictly above $\left(w^{*}\left(\sigma^{\prime}\right), w^{*}\left(\sigma^{\prime \prime}\right)\right)$. This implies, that there are pairs that lie below $\tau \tau$ above $T T$ and below $T^{\prime} T^{\prime}$. This means that if firm 2 offers a contract differing from $w^{*}$ only in that $\left(w^{*}\left(\sigma^{\prime}\right), w^{*}\left(\sigma^{\prime \prime}\right)\right)$ is replaced by a pair such as $\left(\widetilde{w}\left(\sigma^{\prime}\right), \widetilde{w}\left(\sigma^{\prime \prime}\right)\right)$ in Figure 6, it would get a profit strictly larger than $\widetilde{\pi}$ because this contract would be accepted by type $\tau$ only. Given that this offer would be a profitable deviation for firm 2, a contradiction arises. Notice that while Figure 6 depicts a case in which $w^{*}\left(\sigma^{\prime \prime}\right)>w^{*}\left(\sigma^{\prime}\right)$, this inequality is inessential for the result, because the result depends on the difference between the marginal rates of substitution of the two type of manager and the fact that $\tau \tau$, the break-even line for type $\tau$, lies strictly above point $\left(w^{*}\left(\sigma^{\prime}\right), w^{*}\left(\sigma^{\prime \prime}\right)\right)$ but it does not depend on the relative magnitudes of the slopes of $T T$ and $\tau \tau$.

2. The expected profit to a firm whose offer $w^{*}$ is accepted by type $\tau$ is $\pi_{\tau}<\tilde{\pi}$.

By Lemma 2 the expected profit to a firm whose offer $w^{*}$ is accepted by type $\tau^{\prime}$ is

$$
\pi_{\tau^{\prime}}=\frac{\widetilde{\pi}-\operatorname{Pr}(\tau) \pi_{\tau}}{1-\operatorname{Pr}(\tau)}>\widetilde{\pi} .
$$

Consider Figure 7, depicting $T T$ and $T^{\prime} T^{\prime}$, the indifference curves for types $\tau$ and $\tau^{\prime}$ passing through $\left(w^{*}\left(\sigma^{\prime}\right), w^{*}\left(\sigma^{\prime \prime}\right)\right)$ and $\tau^{\prime} \tau^{\prime}$, the set of contracts differing from $w^{*}$ only in that $\left(w^{*}\left(\sigma^{\prime}\right), w^{*}\left(\sigma^{\prime \prime}\right)\right)$ is replaced by $\left(w\left(\sigma^{\prime}\right), w\left(\sigma^{\prime \prime}\right)\right)$ and that conditional on being accepted only by type $\tau^{\prime}$ have the same expected profit as $w^{*}$ when this is accepted by both types, i.e., $\widetilde{\pi}$. Notice that given that $\pi_{\tau^{\prime}}>\widetilde{\pi}$, $\tau^{\prime} \tau^{\prime}$ lies strictly above $\left(w^{*}\left(\sigma^{\prime}\right), w^{*}\left(\sigma^{\prime \prime}\right)\right)$. This implies, that there are pairs that lie below $\tau^{\prime} \tau^{\prime}$ above $T^{\prime} T^{\prime}$ and below $T T$. This means that if firm 2 offers a contract differing from $w^{*}$ only in that $\left(w^{*}\left(\sigma^{\prime}\right), w^{*}\left(\sigma^{\prime \prime}\right)\right)$ is replaced by a pair such as $\left(\widetilde{w}\left(\sigma^{\prime}\right), \widetilde{w}\left(\sigma^{\prime \prime}\right)\right)$ in Figure 7 , it would get a profit strictly larger than $\widetilde{\pi}$ because this contract would be accepted by type $\tau^{\prime}$ only. Given that this offer would be a profitable deviation for firm 2, a contradiction arises. As before, notice that Figure 7 depicts a case in which $w^{*}\left(\sigma^{\prime \prime}\right)>w^{*}\left(\sigma^{\prime}\right)$, but this inequality is inessential for the result. In fact the result holds despite the fact that $w^{*}\left(\sigma^{\prime \prime}\right)>w^{*}\left(\sigma^{\prime}\right)$ implies that $T^{\prime} T^{\prime}$ is steeper at $w^{*}$ than $\tau^{\prime} \tau^{\prime}$, because $\tau^{\prime} \tau^{\prime}$ lies strictly above point $\left(w^{*}\left(\sigma^{\prime}\right), w^{*}\left(\sigma^{\prime \prime}\right)\right)$.

3. The expected profit to a firm whose offer $w^{*}$ is accepted by type $\tau$ is $\pi_{\tau}=\tilde{\pi}$.

By Lemma 2 the expected profit to a firm whose offer $w^{*}$ is accepted by type $\tau^{\prime}$ is

$$
\pi_{\tau^{\prime}}=\frac{\widetilde{\pi}-\operatorname{Pr}(\tau) \pi_{\tau}}{1-\operatorname{Pr}(\tau)}=\widetilde{\pi} .
$$

Notice that $w^{*}$ cannot be a constant contract, because otherwise $\pi_{\tau} \neq \pi_{\tau^{\prime}}$. This implies that there have to be two states of nature, $\sigma^{\prime}$ and $\sigma^{\prime \prime}$ such that the salaries are different from each other $w^{*}\left(\sigma^{\prime}\right) \neq w^{*}\left(\sigma^{\prime \prime}\right)$. Without loss of generality suppose that $w^{*}\left(\sigma^{\prime \prime}\right)>w^{*}\left(\sigma^{\prime}\right)$ and recall that we are assuming that $M R S_{w\left(\sigma^{\prime}\right), w\left(\sigma^{\prime \prime}\right)}^{\tau}\left(w^{*}\right)<M R S_{w\left(\sigma^{\prime}\right), w\left(\sigma^{\prime \prime}\right)}^{\tau^{\prime}}\left(w^{*}\right)$. Consider Figure 8. Given that

$$
M R S_{w\left(\sigma^{\prime}\right), w\left(\sigma^{\prime \prime}\right)}^{\tau}(w)=-\frac{\operatorname{Pr}\left(\sigma^{\prime} \mid \tau\right)}{\operatorname{Pr}\left(\sigma^{\prime \prime} \mid \tau\right)},
$$


when $w\left(\sigma^{\prime \prime}\right)=w\left(\sigma^{\prime}\right), w^{*}\left(\sigma^{\prime \prime}\right)>w^{*}\left(\sigma^{\prime}\right)$ implies that

$$
M R S_{w\left(\sigma^{\prime}\right), w\left(\sigma^{\prime \prime}\right)}^{\tau}\left(w^{*}\right)<-\frac{\operatorname{Pr}\left(\sigma^{\prime} \mid \tau\right)}{\operatorname{Pr}\left(\sigma^{\prime \prime} \mid \tau\right)},
$$

i.e., $T T$, the indifference curve of type $\tau$, is steeper at $w^{*}$ than $\tau \tau$, the set of contracts that have the same expected cost as $w^{*}$ conditioned on only type $\tau$ accepting it. Consider now a contract $w^{\prime}$ which differs from $w^{*}$ in that $\left(w^{*}\left(\sigma^{\prime}\right), w^{*}\left(\sigma^{\prime \prime}\right)\right)$ is replaced by $\left(\widetilde{w}\left(\sigma^{\prime}\right), \widetilde{w}\left(\sigma^{\prime \prime}\right)\right)$ below $\tau \tau$, below $T^{\prime} T^{\prime}$ and above $T T$, as shown in Figure 8. This contract is strictly better for type $\tau$ and strictly worse for $\tau^{\prime}$ and is such that the expected profit, conditional on only type $\tau$ accepting it, is higher than $\widetilde{\pi}$, the expected profit from offering $w^{*}$ and having it accepted by both types. This implies that offering contract $w^{\prime}$ would be a profitable deviation for firm 2, and a contradiction arises.

We now turn to the proof of Proposition 2.

From Lemma 3 we know that in the path of a subgame perfect Nash equilibrium types $B$ and $G$ accept different contracts, $w_{B}$ and $w_{G}$. This requires that

$$
\begin{aligned}
& V^{G}\left(w^{G}\right) \geq V^{G}(w) \\
& V^{B}\left(w^{B}\right) \geq V^{B}(w) .
\end{aligned}
$$

From Lemma 2 we know that firms' equilibrium profits are $\widetilde{\pi}$ and this implies that

$$
\begin{aligned}
& E[\pi-w \mid G]=\widetilde{\pi} \\
& E[\pi-w \mid B]=\pi
\end{aligned}
$$

Notice first that $\left(w^{R S W-B}, w^{R S W-G}\right)$ satisfy conditions (19)-(22). Suppose now that

$$
\left(w^{B}, w^{G}\right) \neq\left(w^{R S W-B}, w^{R S W-G}\right) .
$$

Notice that given that (10) is slack, $w^{R S W-B}$ maximizes type $B$ 's utility subject to (9) and this implies that the utility to $B$ with $w^{R S W-B}$ can be no lower than the utility from $w^{B}$. This in turn implies that the utility to $G$ with $w^{R S W-B}$ can be no lower than the utility from $w^{G}$. Given (23), moreover the utility to at least one of the two types has to be strictly lower than with $\left(w^{R S W-B}, w^{R S W-G}\right)$. This implies that there exists a contract that is no worse for any of the two types, is strictly better for at least one of the two and is such that the unconditional expected profit from offering it is strictly larger than $\widetilde{\pi}$, a contradiction. 


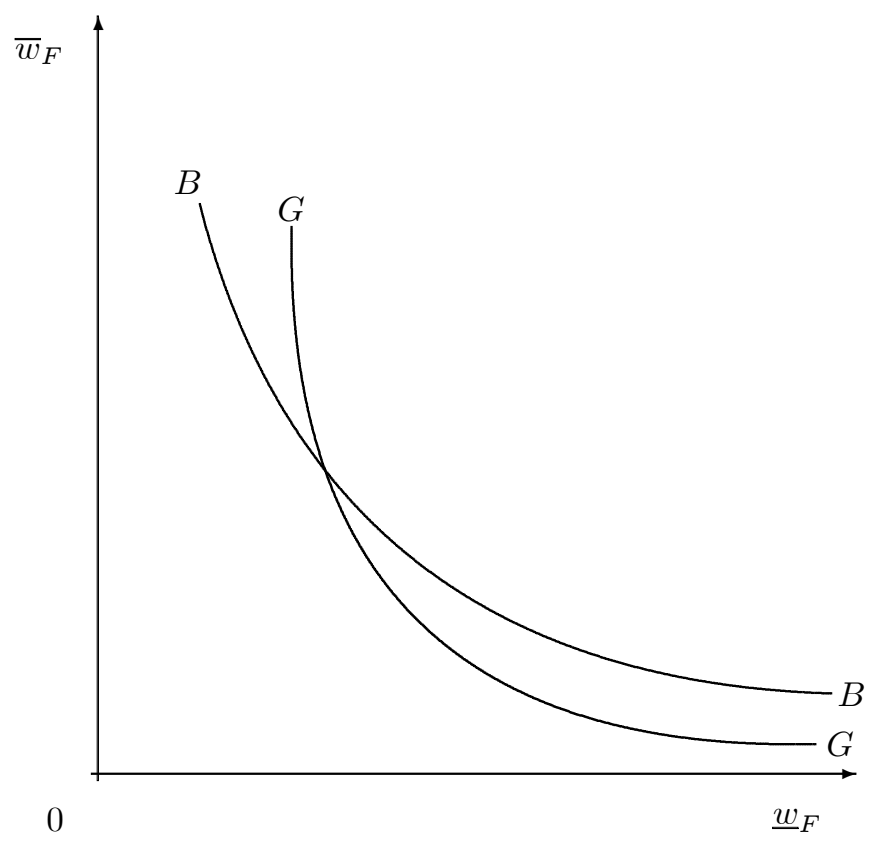

Figure 1(a): Indifference curves of the good and the bad manager with failure $(P=F)$

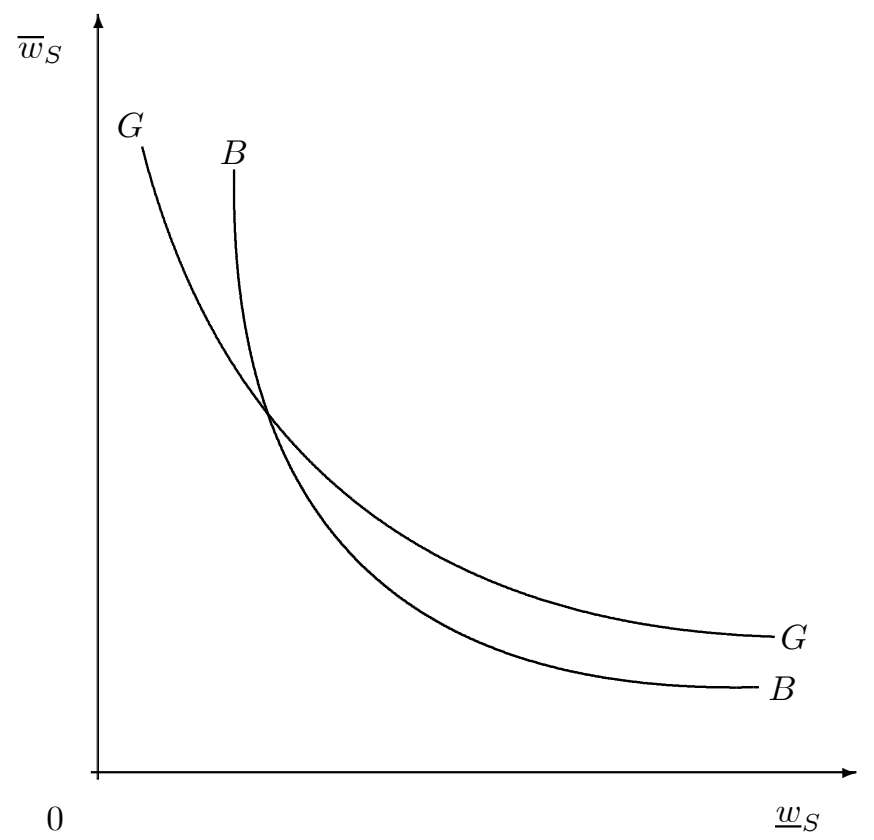

Figure 1(b): Indifference curves of the good and the bad manager with success $(P=S)$ 


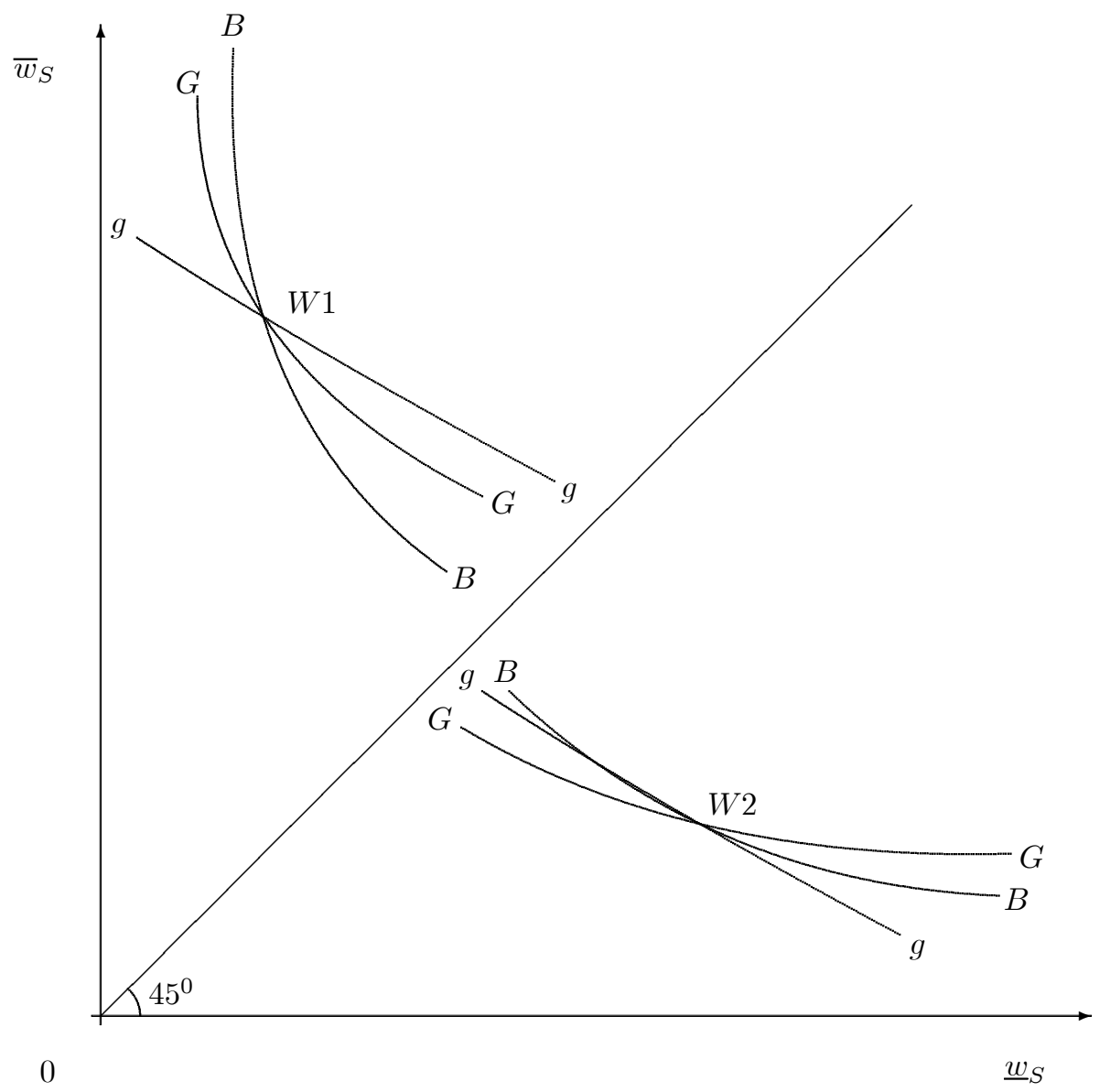

Figure 2 


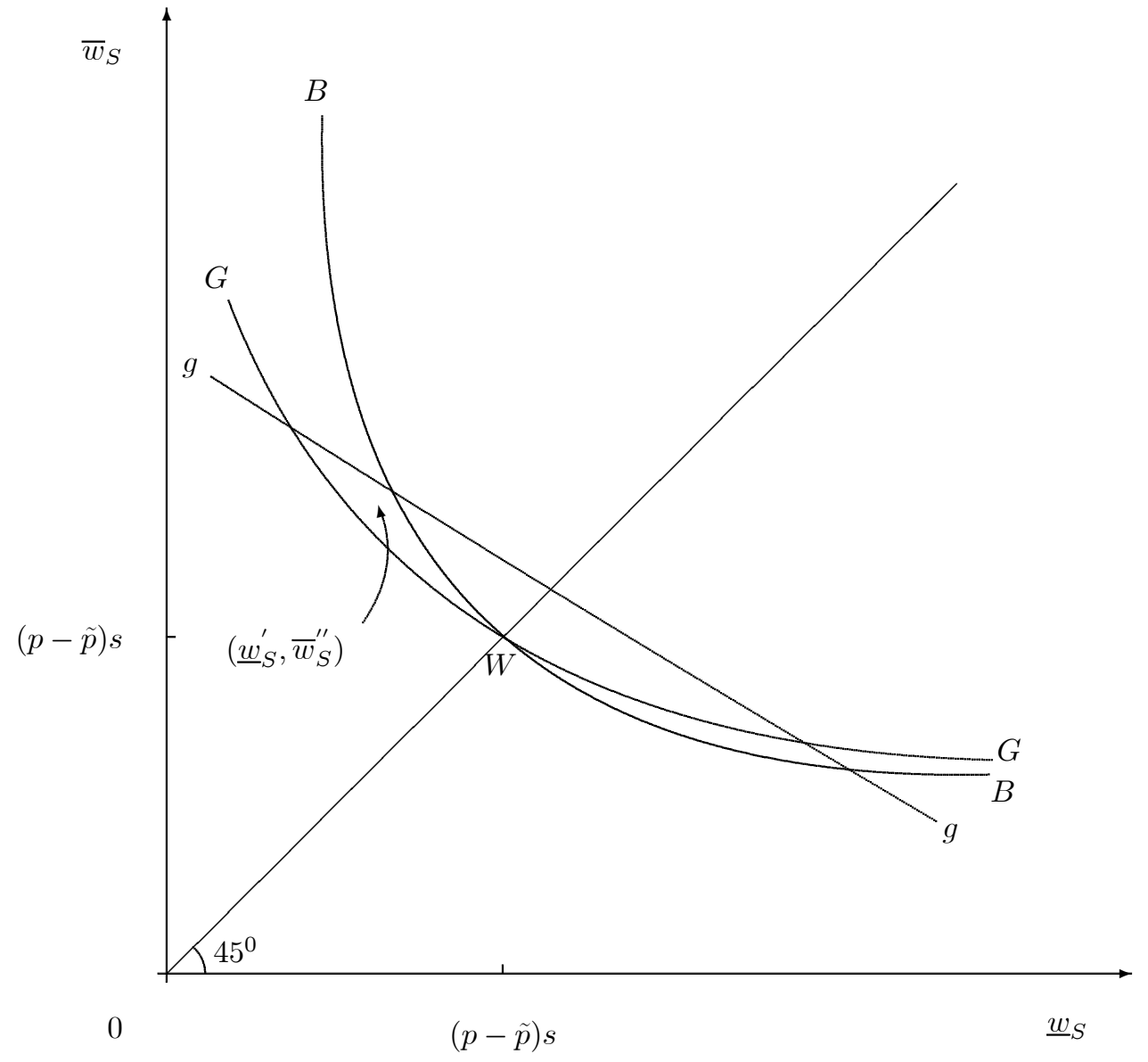

Figure 3 


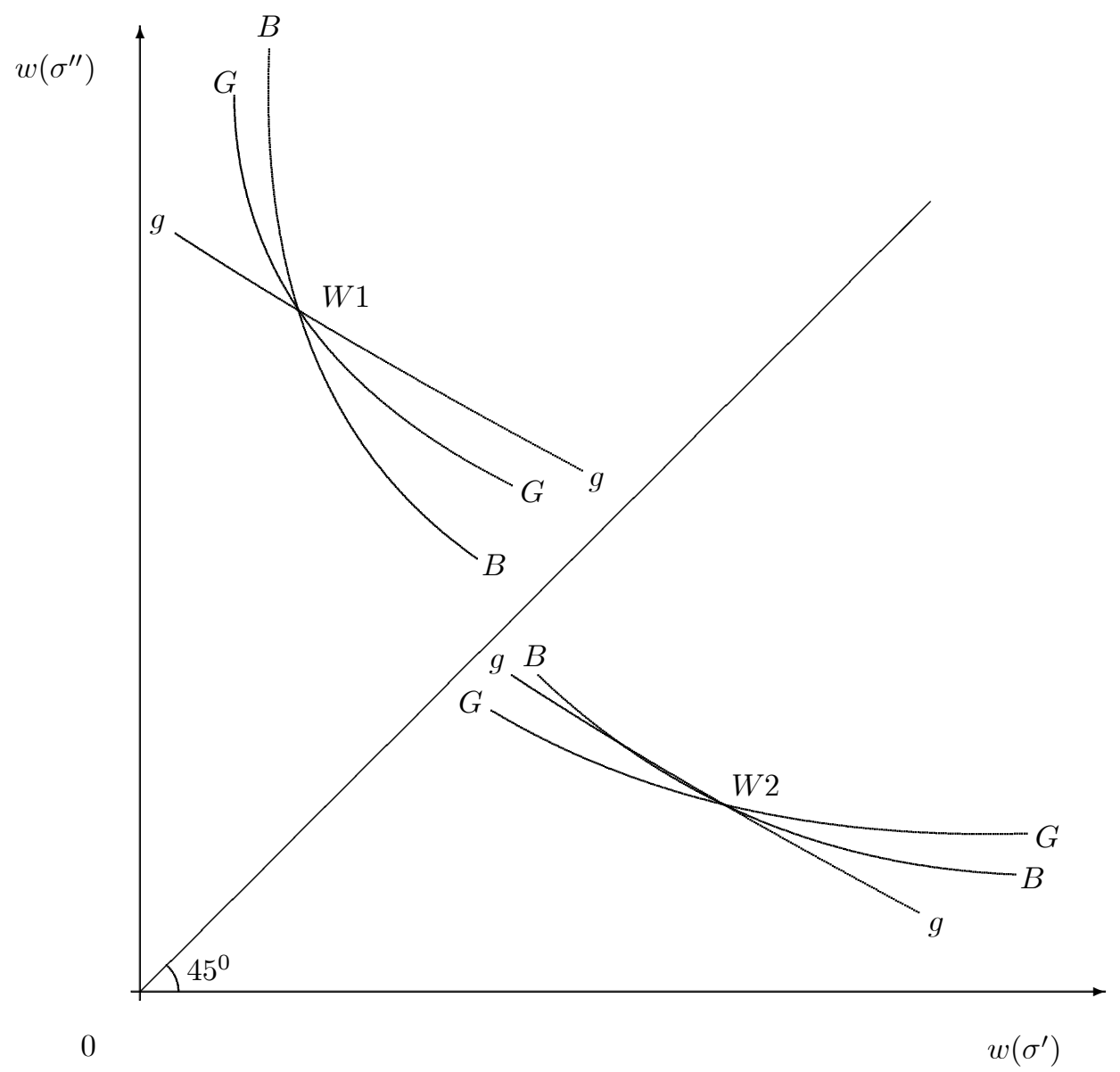

Figure 4 


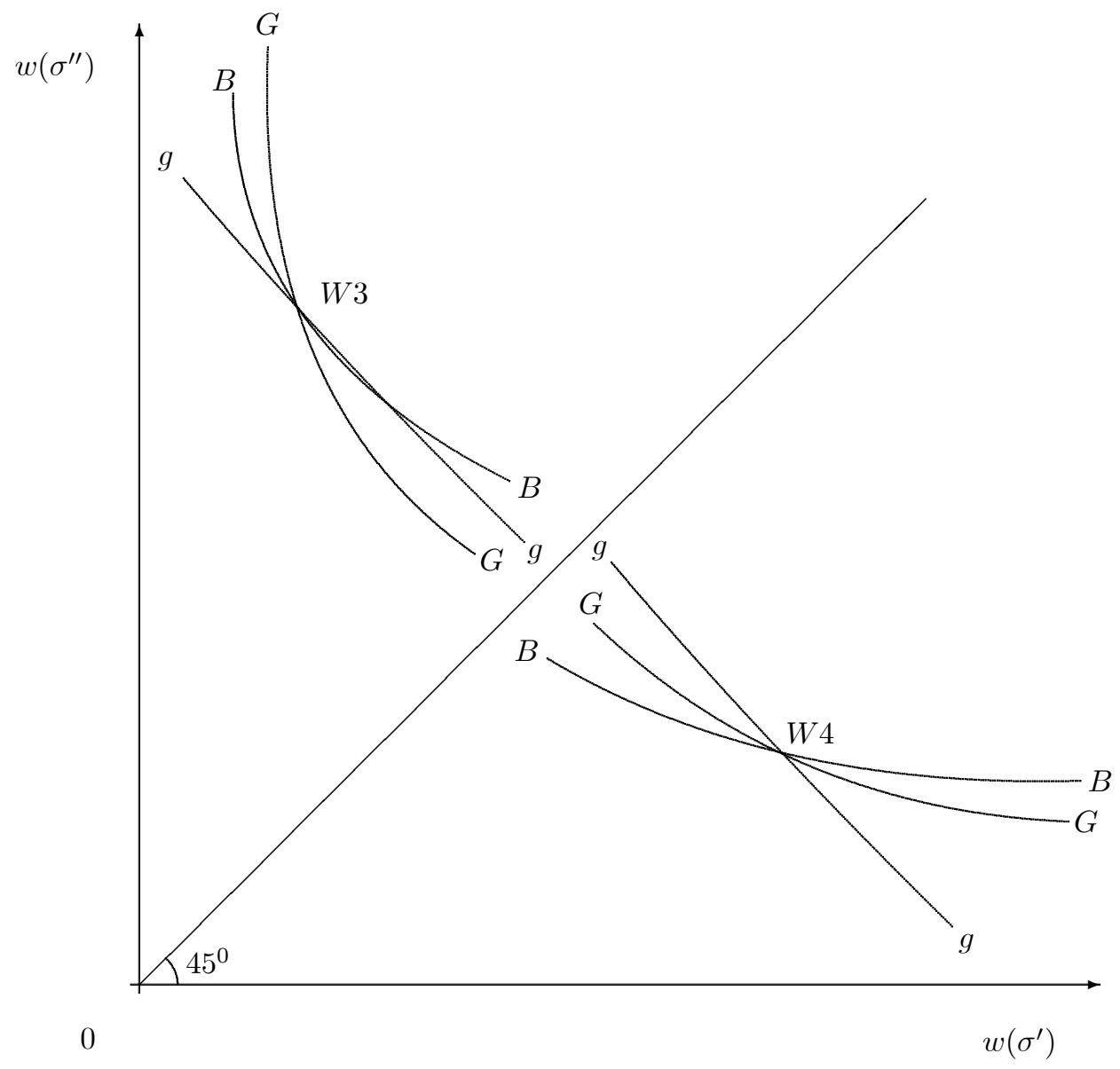

Figure 5 


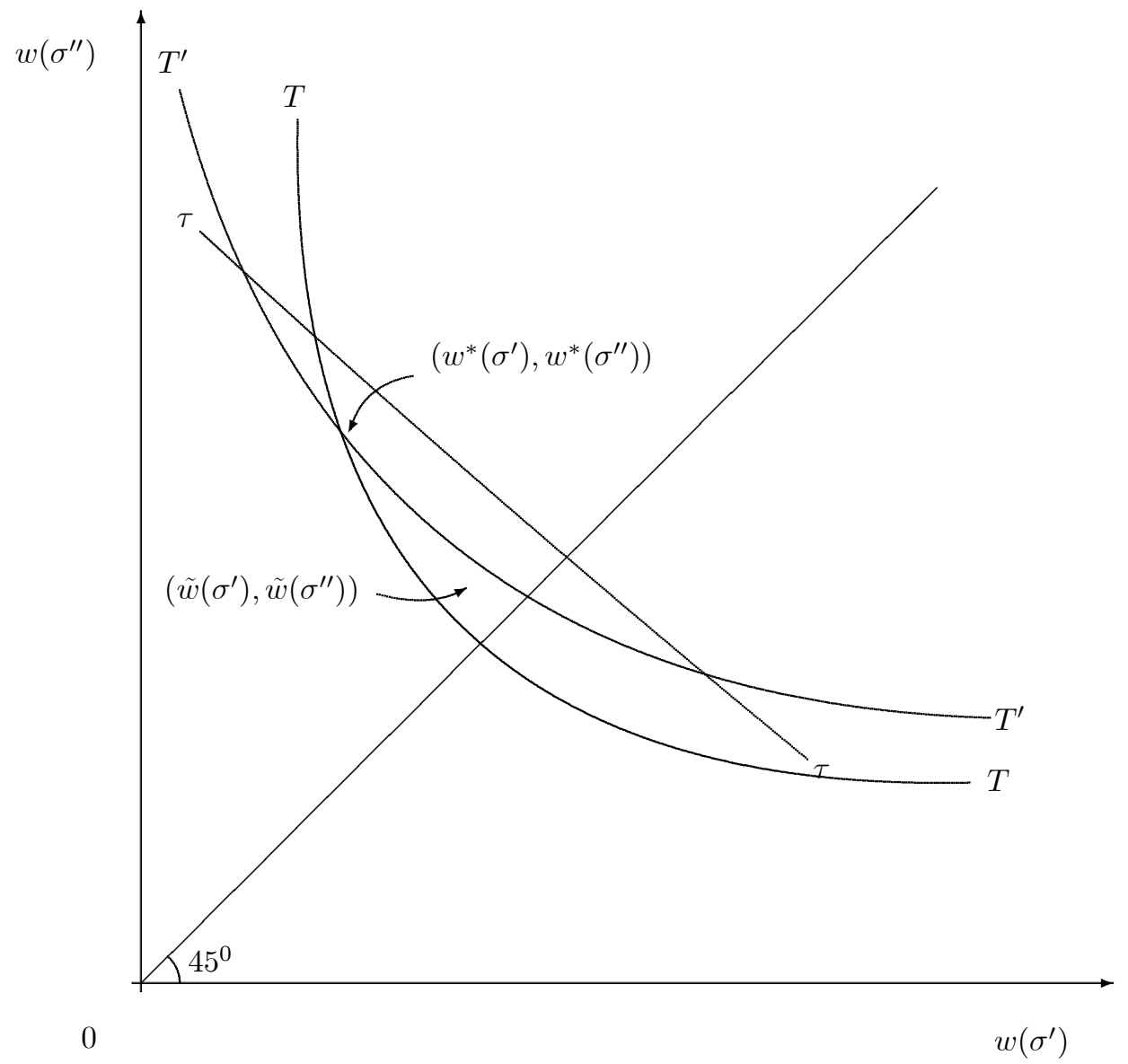

Figure 6 


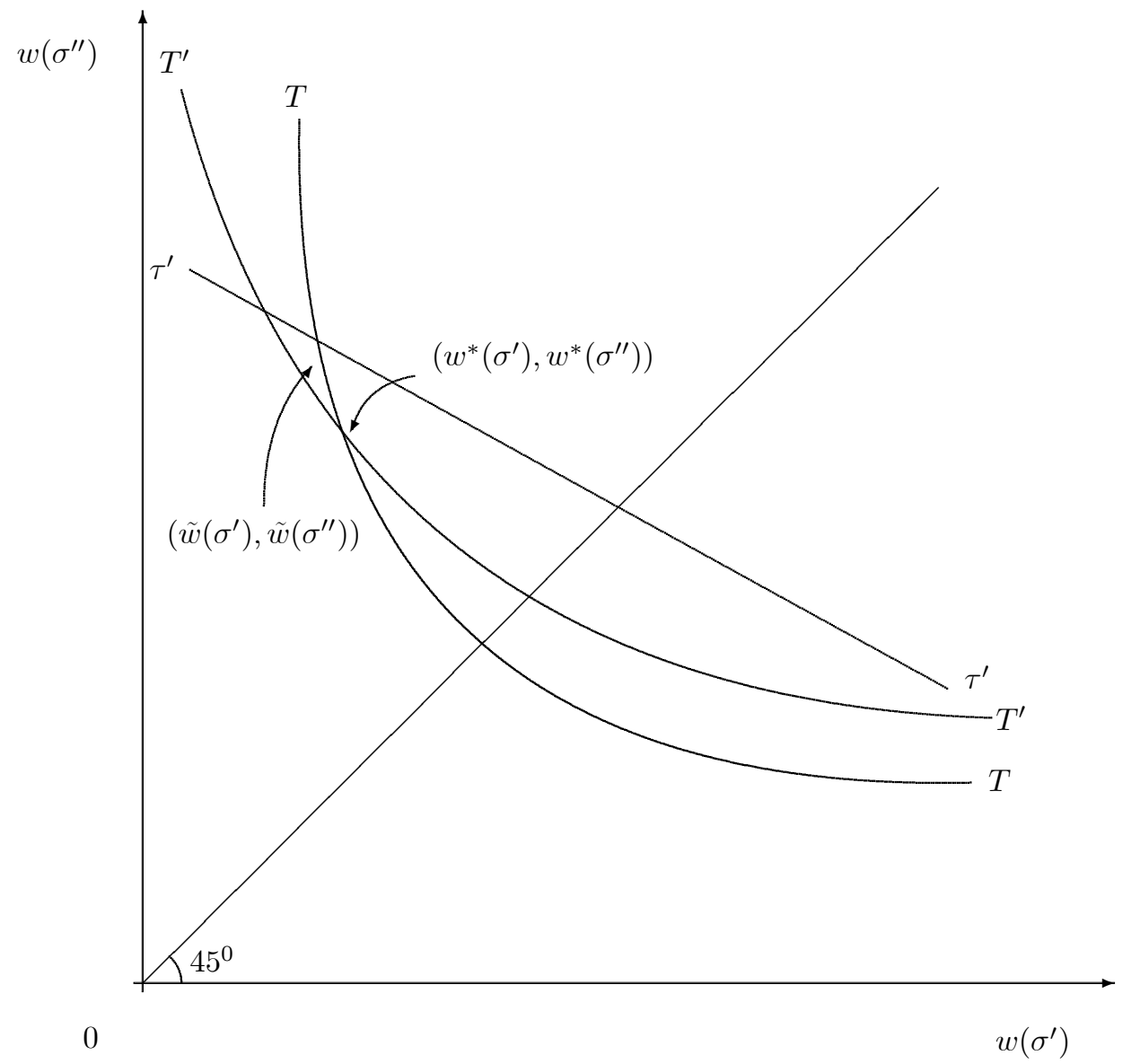

Figure 7 


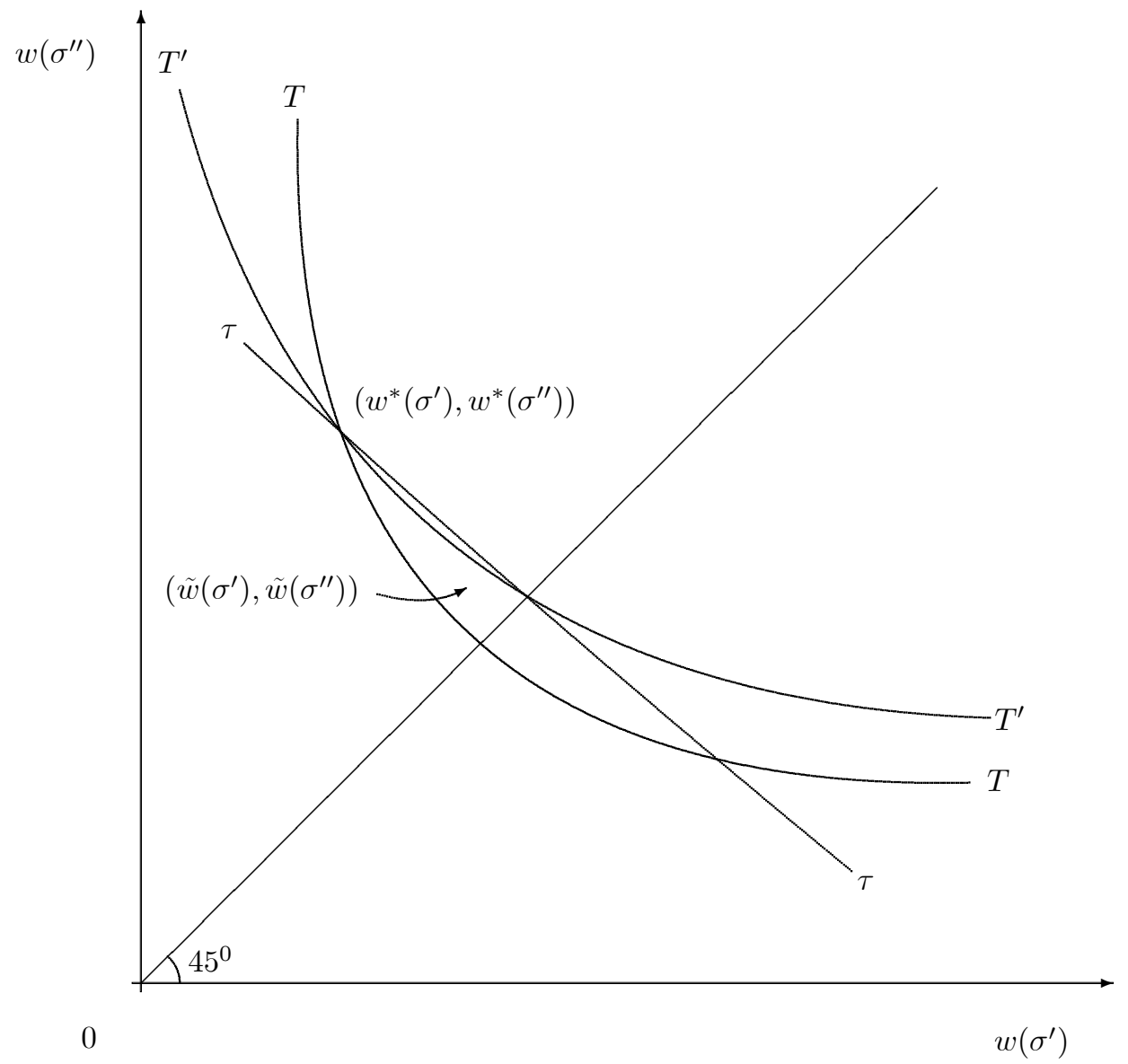

Figure 8 
Table 1

BLP coefficients for

specification (13)

\begin{tabular}{cccc}
$\mu$ & $\beta_{0}$ & $\beta_{1}$ & $\beta_{2}$ \\
\hline \hline 0.2500 & 5.3851 & 0.0365 & 0.0225 \\
\hline 0.3660 & 5.1568 & 0.0533 & 0.0289 \\
\hline 0.5000 & 4.9306 & 0.0727 & 0.0336 \\
\hline 0.6340 & 4.7360 & 0.0920 & 0.0360 \\
\hline 0.7500 & 4.5919 & 0.1087 & 0.0364 \\
\hline
\end{tabular}

